\title{
Current status and future perspectives of gold nanoparticle vectors for siRNA delivery
}

\author{
Álvaro Artigaa, Inés Serrano-Sevillaa, Laura De Matteis ${ }^{b}$, Scott G. Mitchella and Jesús M. de la \\ Fuente $^{\mathrm{a} *}$ \\ Discovering the vast therapeutic potential of siRNA opened up new clinical research areas focussing on a number of diseases \\ and applications; however significant problems with siRNA stability and delivery has hindered its clinical applicability. As a \\ result, interest in the development of practical siRNA delivery systems has grown in recent years. Of the numerous siRNA \\ delivery strategies currently on offer, gold nanoparticles (AuNPs) stand out thanks to their biocompatibility and capacity to \\ protect siRNA against degradation; not to mention the versatility offered by their tuneable shape, size and optical properties. \\ Herein this review provides a complete summary of the methodologies for functionalizing AuNPs with siRNA, paying singular \\ attention to the AuNP shape, size and surface coating, since these key factors on heavily influence cellular interaction, \\ internalization and, ultimately, the efficacy of the hybrid particle. The most noteworthy hybridization strategies have been \\ highlighted along with the most innovative and outstanding in vivo studies with a view to increasing clinical interest in the \\ use of AuNPs as siRNA nanocarriers.
}

\section{Background}

Since Fire, Mello and colleagues discovered the ability of RNA to silence gene expression in Caenorhabditis elegans in 1998, ${ }^{1}$ the interest in RNA interference (RNAi) as a tool for treating a widerange of diseases has increased exponentially. Although RNA interference is a regulatory mechanism naturally present in a variety of eukaryotic organisms including fungi, plants and animals, the therapeutic importance of RNAi was best demonstrated in 2001 when Elbashir et al utilized synthetic small interfering RNAs (siRNAs) to achieve gene-specific knockdown in a mammalian cell line. ${ }^{2}$ The following year marked another milestone when the first in vivo study applying RNAi was reported. In this investigation, the research group of Mark A. Kay showed that transgene luciferase expression could be suppressed in adult mice by synthetic small interfering RNA (siRNA) and short hairpin RNAs (shRNA). ${ }^{3}$ These pioneering results showed how the robust silencing effect of RNAi represented an extremely valuable research tool that was able to inhibit the messenger RNA (mRNA) translation process. Moreover, they also illustrated how a hitherto unknown therapeutic agent could be used against various disease targets, including (but not limited to) viral infections, ${ }^{4}$ hereditary disorders ${ }^{5}$ and cancer. ${ }^{6}$

These landmark achievements in therapeutic RNAi research would not have been possible without a fundamental understanding of RNAi itself. The biochemical pathways for RNAi activity are varied and wide-ranging and several types of RNAs have been connected to the interference pathway: including highly conserved endogenous non-coding microRNA (miRNA), shRNA normally encoded in an exogenous expression vector and siRNA. ${ }^{7}$ Although the initial steps of the RNAi mechanism differ strongly from one type of RNA to another (shRNA, siRNA or miRNA), all involve the interaction of RNA with a protein complex that specifically recognizes and cleaves a messenger RNA (mRNA). While various exogenous RNA can be used for therapeutic purposes, the scientific literature has tended to focus on siRNA due to its simplicity and the ease by which it can be conjugated to nanostructured delivery systems. For these reasons, this text is based solely on the use of siRNA and does not cover the use of other RNAi molecules. Synthetic siRNA are usually produced as double-stranded RNA of 21-to-23 nucleotides long with two nucleotides overhanging on the $3^{\prime}$ ends, showing a similar structure to the natural products of cleaved double-stranded RNA by the Dicer enzyme that takes part in the intrinsic regulatory mechanism. ${ }^{8}$ 


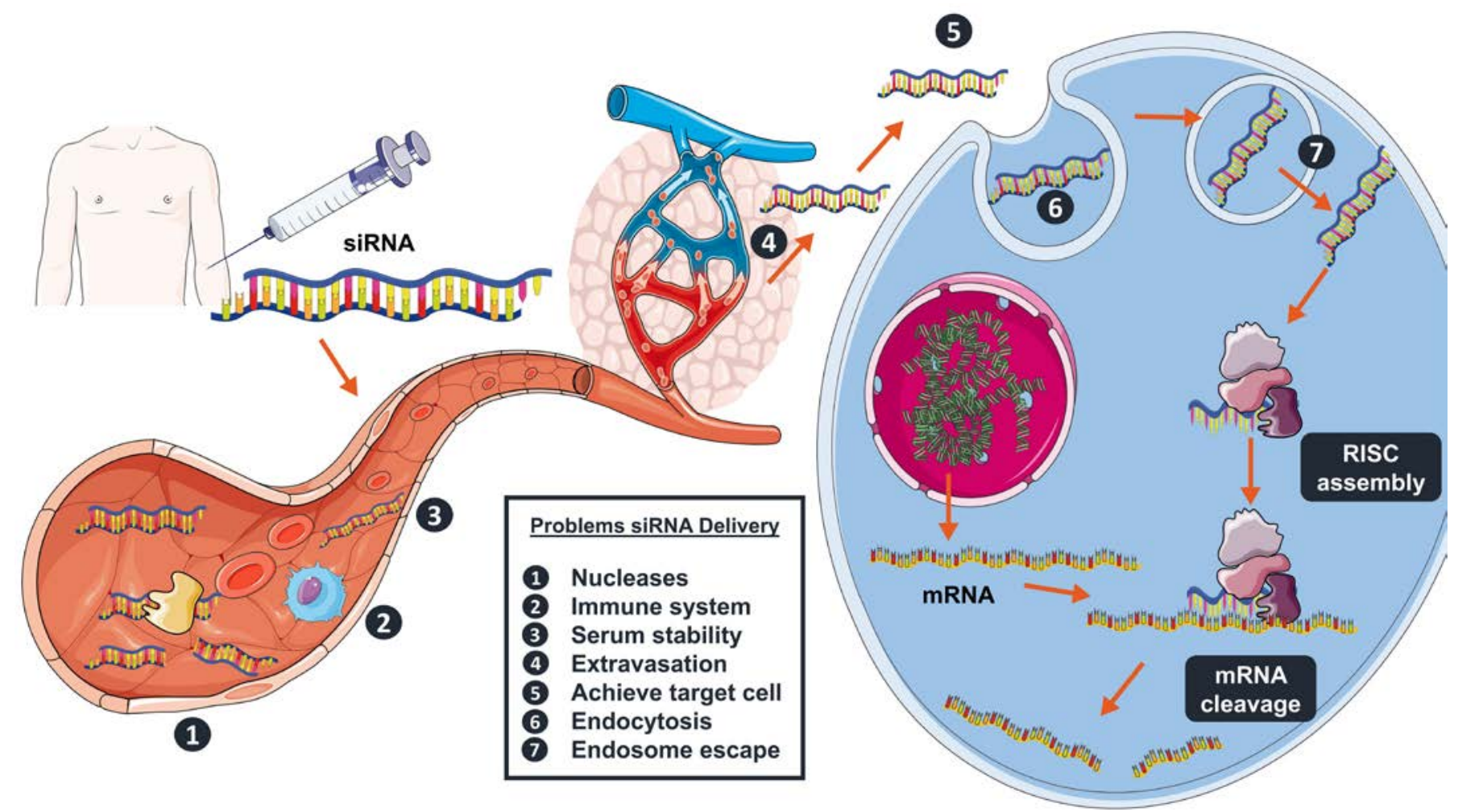

Figure 1. Overview of siRNA delivery problems that must be overcome, accompanied by a simplified cytoplasmic molecular scheme of siRNA biochemical mechanism. This figure was produced using elements from the Servier Medical Art PowerPoint image bank.

Importantly, siRNA should be delivered to the cell cytoplasm where the gene-silencing action takes place. There, siRNA interacts with a protein complex called the RNA-induced silencing complex (RISC) producing the RNA strands separation, ${ }^{9}$ as seen in Figure 1 . While the passenger strand is degraded, the RISC complex - still joined to the guide strand recognizes the messenger RNA (mRNA) complementary to the guide strand and catalyzes its cleavage. ${ }^{10}$ This activated RISC complex will continue degrading the specific mRNA, causing a transient descent on protein expression. Studies have shown how the duration of the interference effect varies markedly from one type of cells to another: the duration of gene silencing in rapidly growing cell lines lasts a few days while this increases to approximately three weeks in non-dividing cells. ${ }^{11}$ This difference is produced in part due to dilution of siRNA inside the cytoplasm as a result of cell division; however, the interference effect can be prolonged by administration of several siRNA doses. ${ }^{11}$

The route of administration is a critically important factor that should be considered when applying siRNA ${ }^{12}$ since each delivery route poses a variety of barriers and problems before the siRNA can reach the cell cytoplasm to perform its function. This is particularly important in the case of systemic administration, which shows a specific complexity due to the numerous factors that compose the biological response to exogenous siRNA ${ }^{13}$ (refer to Figure 1 for details). Systemic administration introduces siRNA molecules directly into the blood torrent, where they can be subjected to hydrolysis by various serum nucleases ${ }^{14}$ and the innate immune system, which in some cases can recognize them in a sequencedependent manner. ${ }^{15}$ Naked siRNA is also rapidly eliminated by renal clearance, showing a serum half-life of less than five minutes, ${ }^{4}$ and it can be also excreted via the intestine by the hepatobiliary pathway. ${ }^{16}$ To stand any chance of performing their desired function at the target cells, siRNA must first cross the vascular endothelium. ${ }^{17}$ Once at the target site, siRNA molecules are too large and hydrophilic to diffuse across the cytoplasmic membrane, ${ }^{18}$ meaning that internalization most often occurs via endocytosis, which occurs through a host of different mechanisms such as phagocytosis, macropinocytosis, clathrin-mediated endocytosis and caveolae-mediated endocytosis depending on the cell type. ${ }^{13}$ In an ideal scenario, endocytic internalization concludes with the siRNAs contained within cytoplasmic vesicles such as the endosomes, although siRNAs must then escape from these intracellular vesicles into the cell cytosol to participate in the cellular RNAi machinery to carry out their function.

The incredible potential of siRNA for medical applications became evident in 2006 when Fire and Mello won the Nobel Prize in Physiology or Medicine for their discovery of RNA interference. This discovery has since then stemmed thousands of scientific publications about siRNAs and their delivery and, in parallel, thousands of related patents have been registered concerning the future drug technology. More precisely, by the year 2007 more than 2000 RNAi patent applications had been filled in the US Patent and Trademark Office. ${ }^{19}$ After seven years, in 2014, the company Alnylam Pharmaceuticals possessed a predominant position on RNAi market, performing 
six different clinical trials, one of them in Phase III. ${ }^{20}$ Recently however, in October 2016, Alnylam Pharmaceuticals had to put an abrupt end to the Phase III clinical trial of one of their two core products due to 18 patient deaths provoking a fall in
Alnylam shares of $48 \%$, and increasing doubts about RNAi future in real clinical treatment.

Table 1. Summary of the most recently published and promising clinical trials on gene silencing using siRNA. The table includes information about the type of siRNA carrier, the target protein, the patients treated, the administration route and a summary of the principle result of the study.

\begin{tabular}{|c|c|c|c|c|c|c|}
\hline Registration Code & $\begin{array}{c}\text { Year of } \\
\text { publication }\end{array}$ & Target & Patients & Administration & Vehicle & Results summary \\
\hline NCT00363714 ${ }^{21}$ & 2010 & $\begin{array}{l}\text { Vascular endothelial } \\
\text { growth factor } \\
\text { receptor-1 }\end{array}$ & $\begin{array}{l}26 \text { patients with } \\
\text { neovascular age- } \\
\text { related macular } \\
\text { degeneration (AMD) }\end{array}$ & $\begin{array}{l}\text { Intravitreal } \\
\text { injection }\end{array}$ & $\begin{array}{c}\text { Chemically } \\
\text { modified siRNA }\end{array}$ & $\begin{array}{l}\text { Improvement in } \\
\text { visual acuity and } \\
\text { foveal thickness }\end{array}$ \\
\hline NCT00689065 22 & 2010 & $\begin{array}{l}\text { Ribonucleoside- } \\
\text { diphosphate } \\
\text { reductase subunit } \\
\text { M2 (RRM2) }\end{array}$ & $\begin{array}{l}3 \text { patients with solid } \\
\text { cancers } \\
\text { refractory to } \\
\text { standard-of-care } \\
\text { therapies }\end{array}$ & $\begin{array}{l}\text { Intravenous } \\
\text { infusion }\end{array}$ & $\begin{array}{l}\text { Targeted Protein- } \\
\text { Polymeric-siRNA } \\
\text { Nanoparticle }\end{array}$ & $\begin{array}{l}\text { Decrease in RRM2 } \\
\text { expression }\end{array}$ \\
\hline NCT00658086 & 2011 & RSV N protein & $\begin{array}{l}24 \text { lung transplanted } \\
\text { patients infected } \\
\text { with Respiratory } \\
\text { Syncytial Virus (RSV) }\end{array}$ & $\begin{array}{l}\text { Respiratory } \\
\text { system } \\
\text { nebulization }\end{array}$ & $\begin{array}{l}\text { Unmodified } \\
\text { SiRNA }\end{array}$ & $\begin{array}{l}\text { Symptoms } \\
\text { decrease }\end{array}$ \\
\hline NCT00672542 25 & 2013 & $\begin{array}{c}3 \text { inducible } \\
\text { immunoproteasome } \\
\text { subunits }\end{array}$ & $\begin{array}{l}12 \text { patients with } \\
\text { metastatic } \\
\text { melanoma }\end{array}$ & \multicolumn{2}{|c|}{$\begin{array}{l}\text { Intradermal injections of dendritic } \\
\text { cells externally electroporated with } \\
\text { unmodified siRNA }\end{array}$} & $\begin{array}{l}\text { Circulating } \\
\text { melanoma cell } \\
\text { levels fell }\end{array}$ \\
\hline NCT0093857426 & 2014 & Protein kinase N3 & $\begin{array}{l}34 \text { patients with } \\
\text { advanced solid } \\
\text { tumors }\end{array}$ & $\begin{array}{l}\text { Intravenous } \\
\text { infusions }\end{array}$ & $\begin{array}{l}\text { Liposomal } \\
\text { particles }\end{array}$ & $\begin{array}{l}\text { Disease } \\
\text { stabilization in } \\
\text { some patients }\end{array}$ \\
\hline NCT0143705927 & 2014 & $\begin{array}{c}\text { Proprotein } \\
\text { convertase } \\
\text { subtilisin/kexin type } \\
9 \text { (PCSK9) }\end{array}$ & $\begin{array}{l}32 \text { healthy adult } \\
\text { volunteers with } \\
\text { elevated LDL- } \\
\text { cholesterol }\end{array}$ & $\begin{array}{c}\text { Intravenous } \\
\text { administration }\end{array}$ & $\begin{array}{c}\text { Lipid } \\
\text { nanoparticle }\end{array}$ & $\begin{array}{l}\text { Reduction in PCSK9 } \\
\text { plasma protein and } \\
\text { LDL cholesterol }\end{array}$ \\
\hline NCT01188785 28 & 2015 & Mutated KRAS(G12D) & $\begin{array}{l}15 \text { patients with non- } \\
\text { operable Locally } \\
\text { Advanced Pancreatic } \\
\text { Cancer (LAPC) }\end{array}$ & $\begin{array}{l}\text { Tumor } \\
\text { insertion }\end{array}$ & $\begin{array}{l}\text { Biodegradable } \\
\text { polymer implant }\end{array}$ & $\begin{array}{l}\text { Decrease in tumor } \\
\text { marker CA19-9 }\end{array}$ \\
\hline NCT0143828129 & 2016 & $\begin{array}{l}\text { Transient receptor } \\
\text { potential cation } \\
\text { channel subfamily V } \\
\text { member } 1 \text { (TRPV1) }\end{array}$ & $\begin{array}{l}156 \text { healthy subjects } \\
\text { and patients with Dry } \\
\text { Eye Disease (DED) }\end{array}$ & $\begin{array}{c}\text { Topical } \\
\text { administration }\end{array}$ & $\begin{array}{l}\text { Unmodified } \\
\text { SiRNA }\end{array}$ & $\begin{array}{l}\text { Safe treatment and } \\
\text { Visual Analogue } \\
\text { Scale (VAS) } \\
\text { improvement }\end{array}$ \\
\hline
\end{tabular}


Surprisingly, despite the large amount of siRNA patents registered, only 63 clinical trials concerning siRNA have been registered between the U.S. National Institutes of Health and the EU Clinical Trials Register and only one siRNA-based therapeutic drug has been recently approved in August 2018. This drug, Onpattro (patisiran), is a lipid complex to delivery siRNA to treat polyneuropathy caused by an illness called hereditary transthyretin-mediated amyloidosis (hATTR amyloidosis).

The relatively low number of clinical trials carried out to completion provides an idea of just how little is currently known about siRNA delivery and the aforementioned problems, and therefore illustrates that a significant amount of studies should be performed to apply this technology effectively for any of the many potential therapeutic purposes. Despite the extensive bibliography described for siRNA delivery, a wide part of it has studied the RNA interference of artificial reporter genes, such as luciferase gene and green fluorescent protein (GFP) gene. Although the employment of cell cultures provide an easy way to evaluate their efficiency in preliminary studies, animal cases present complexities that these models do not mimic. For this reason, more abundant efforts should be performed to study the siRNA delivery in real therapeutic genes and pre-clinical animal models in order to allow rapid, cost- and time-effective screenings. ${ }^{30}$

\section{1. siRNA delivery strategies}

Due to these siRNA delivery problems in real applications, recently researchers have focused their efforts to develop different strategies to improve pharmacokinetic profiles in order to achieve gene silencing by RNAi in medical treatments. Some of the best options for therapeutic clinical usage involve chemically modified siRNAs or the use of delivery systems as siRNA vehicles, for example using polymeric, lipidic or inorganic nanoparticles, to transport the siRNA through the body and direct it to the site of action while simultaneously protecting the siRNA against degradation. The most promising siRNA clinical trials that have shown favorable results are detailed in Table 1 where the majority of these examples have employed strategies such as modified-siRNA or the use of siRNA delivery carriers. These trials are described briefly in the following pages.

As seen in Table 1, unmodified siRNA can be used in some specific applications when the administration route allows direct contact between the siRNA and the desired tissue where there is an absence of barriers or delivery problems to overcome. For example, naked siRNA has proven useful for treating skin disorders where it can be injected directly in the skin $^{23}$ and also when it is nebulized for treatment against viruses of the respiratory system. ${ }^{24}$ Another interesting application of this naked siRNA appears when the target cells can be extracted from the patient and the siRNA can be artificially introduced into their cytoplasm, as for the case of dendritic cells. ${ }^{25}$ This approach solves most of the siRNA delivery problems and allows a more effective administration, however it can only be employed in a few of the potential siRNA applications and complicates considerably the treatment process.

The range of applications of unmodified siRNA can be amplified introducing chemical modifications. For instance, modification of the ribose 2'-OH position (particularly by 2'-Omethyl or 2'-fluoro) provides improved plasma stability against nucleophilic attack of $2^{1}-\mathrm{OH}$ by several nucleases ${ }^{31}$ and allows a reduction in siRNA immunogenicity. ${ }^{32}$ The most frequently employed chemical modifications of siRNA are 2'-O-methyl, locked nucleic acid, 2'-deoxy and 2'-fluoro. ${ }^{33}$ Although chemically modified siRNAs can improve the applicability of siRNA and they have been employed successfully for local administration such as intravitreal injection in clinical trial, ${ }^{21}$ they do not overcome other delivery problems such as renal clearance.

Another proposed siRNA delivery method consists of the employment of viral delivery systems, using for example adenovirus, lentivirus and retrovirus vectors. Proof-of-concept studies of viral delivery systems have been demonstrated in animal models of neurodegenerative diseases, retinal diseases, cardiac disease, viral infections, cancer, and many other diseases. ${ }^{34}$ Nevertheless, viral vectors present several drawbacks as immunogenicity, carcinogenicity, and inflammation, limiting their application in clinical treatment. ${ }^{35}$ Consequently, researchers have searched for improved siRNA delivery systems and the use of nanomaterials as siRNA carriers has emerged as a suitable solution with multiple advantages.

Nanoparticles have demonstrated a broad utility and unique versatility for drug delivery and their use in clinical applications is certain to increase exponentially in the years to come. Nanoparticles are showing promising results as drug carriers even although a low amount of the administered dose is typically found in the desired tissue. ${ }^{36}$ It therefore stands true that their efficiency will be enhanced - and their side effects will be decrease - if their targeting efficiency can be improved.

The association of siRNA to different nanocarriers can be carried out through three different strategies: adsorption, covalent binding or encapsulation inside the material. The selection of the most appropriate nanomaterial depends on the final application and the corresponding route of administration and for the resulting material to be effective, both should be designed in concordance. As an illustrative example, a nanomaterial carrying RNA for systemic administration should be engineered to provide stability against plasma nucleases, evasion of the immune system, avoidance of non-specific interactions with plasma proteins and non-target cells, prevention of renal clearance, exit from blood vessels to reach target tissues, cell entry and incorporation into the RNAi machinery. ${ }^{18}$ Much of the research and most important results concerning siRNA delivery have been obtained using lipidic and polymeric nanomaterials, as previously described lipidic Onpattro (patisiran), the only registered drug that employs siRNA. Liposomal nanoparticles have been successfully employed for intravenous administration of siRNA in patients with solid tumors ${ }^{26}$ and elevated cholesterol, ${ }^{27}$ and they are 
currently being evaluated for efficacy in patients from Sierra Leona who have been infected with the Ebola virus, following initial proof of their effectiveness in infected rhesus monkeys. ${ }^{37}$

One of the main advantages of using nanomaterials for siRNA is that they can be used as multifunctional tools, carrying not only the siRNA but also other molecules of interest to increase siRNA efficiency such as other drugs, antibodies, internalization peptides and enzymes (See 3.1 Targeted delivery and 3.2 Co-delivery of other drugs Sections). One such example of a multifunctional nanocarrier is the CALAA-01 nanoparticle that has been tested clinically in patients with solid tumors. CALAA-01 is a polymeric nanoparticle composed of multiple components including a linear cyclodextrin-based polymer, a ligand targeting human transferrin protein to engage transferrin receptors on the surface of the cancer cells, a hydrophilic polymer (polyethylene glycol (PEG) used to promote nanoparticle stability in biological fluids), and siRNA included specifically to reduce the expression of the ribonucleosidediphosphate reductase subunit M2 (RRM2).22 Several other classes of nanomaterials have been employed for siRNA delivery: mesoporous silica nanoparticles, ${ }^{38}$ magnetic nanoparticles, ${ }^{39}$ carbon nanotubes, ${ }^{40}$ graphene, ${ }^{41}$ quantum dots, ${ }^{42}$ calcium phosphate nanoparticles, ${ }^{43}$ gold nanoparticles ${ }^{44}$ and oligonucleotide nanoparticles, ${ }^{45}$ although generally there are fewer of these examples in the literature.

From all of the aforementioned siRNA delivery systems, gold nanoparticles (AuNPs) stand out due to their unique optical properties and their relative inertness and corresponding biocompatibility coupled with the ability to control their size, shape and surface functionalization on the nano and molecular level, in contrast to other inorganic carriers such as silica nanoparticles, iron oxide nanoparticles and quantum dots. Not to mention their capacity to protect siRNA against RNase degradation, probably provoking steric hindrance between the RNases and the siRNA and preventing physical contact with the catalytic site of the enzyme. Although there is an extensive amount of literature on RNA-conjugated AuNPs as nanocarriers, a concise summary of the most relevant studies is lacking. This review focuses on summarizing the available siRNA-AuNP functionalization methodologies in order to maximize RNA interference, paying special attention to the importance of AuNP shape, size and surface coating. The most innovative and applicable approaches for increasing siRNA efficacy have been included and we have endeavored to gather the most noteworthy studies from the field to discuss the potential of these hybrid nanomaterials with a view towards their application in a clinical setting.

\section{Designing the most appropriate gold nanoparticle (AuNP) as a carrier for siRNA therapeutics}

Gold nanoparticles (herein AuNPs) have been shown genuinely useful for nucleic acid delivery; ${ }^{46}$ however, if anything can be derived from the vast amount of literature on the subject it is that there is no universal AuNP for siRNA delivery. In contrast, one of the principle advantages of using AuNPs is that they can be engineered specifically for the desired application and route of administration by the design of the most appropriate size, shape, surface coating and functionalization strategies for each purpose. These are the primary considerations that should be taken into account for AuNP-mediated delivery of siRNA, the details of which are discussed in the following paragraphs.

\subsection{Choosing the most appropriate AuNP size and shape}

Although Faraday carried out the first documented studies on gold colloid synthesis in 1857,47 the previous two decades have witnessed an exponential increase in the number of publications and nowadays thousands of scientific papers concerning gold nanoparticle synthesis are published each year. A number of different synthetic routes can be used to produce AuNPs of different sizes and morphologies, both of which represent critical factors for determining their own individual optical properties, cellular interactions and biodistribution properties. One further critical factor worth considering is the avoidance of toxic compounds in the AuNP synthesis, since residual traces often remain associated to the surface of the nanoparticle: impurities which can also undermine their applicability in biological studies.

Selecting the correct type of AuNP may seem like a trivial parameter, but key factors such as the yield and scalability of the nanoparticle synthesis acquires critical significance to be employed in a real world clinical setting. Almost any kind of AuNP shape can be obtained through numerous conventional synthetic routes (Figure 2), and in the majority of cases the size of the AuNP can be controlled with ease by changing one of a few key experimental parameters during their synthesis, e.g. reagent concentration, reaction time, solution $\mathrm{pH}$, reduction potential, ionic strength, and so forth. ${ }^{48-50}$

The size of AuNPs strongly influences the cellular interaction and internalization pathways, uptake efficiency and cytotoxicity. Despite efforts in AuNP cellular internalization studies, the huge amounts of sizes and shapes and the dependence of internalization rates on cell type make internalization processes of AuNPs difficult to predict. In addition, the surface coating of AuNPs strongly modifies these processes. It is generally accepted that AuNPs are internalized by different uptake pathways in a size-dependant manner ${ }^{51}$ and, in general terms, smaller AuNPs have a higher probability to be passively internalized and usually cause higher toxicity than their larger counterparts (particles of same shape but different size). ${ }^{52}$ When AuNPs are administered intravenously, they must remain in the bloodstream in order to reach their site of action or desired target avoiding renal clearance and immune system elimination. The pore size of glomerulus (located in the kidneys) is $c a .8 \mathrm{~nm}$, and for this reason nanomaterials used for drug delivery purposes tend to be larger than $20 \mathrm{~nm}$ in diameter in order to avoid renal clearance. ${ }^{18}$ This concept has been verified by Hirn et al., showing that spherical AuNPs of 1.4, 2.8 and $5 \mathrm{~nm}$ were found in mice urine but not the 18, 80 and 200 $\mathrm{nm}$ variants. ${ }^{53} \mathrm{In}$ a similar experiment, De Jong and co-workers 
administered spherical AuNPs of 10, 50, 100 and $250 \mathrm{~nm}$ intravenously and the highest amounts of gold were subsequently detected in the blood, liver and spleen. ${ }^{54}$ Of these four AuNP sizes, the $10 \mathrm{~nm}$ AuNPs accumulated in the different organs more than any other size and the highest amount of $\mathrm{Au}$ was found in the liver.

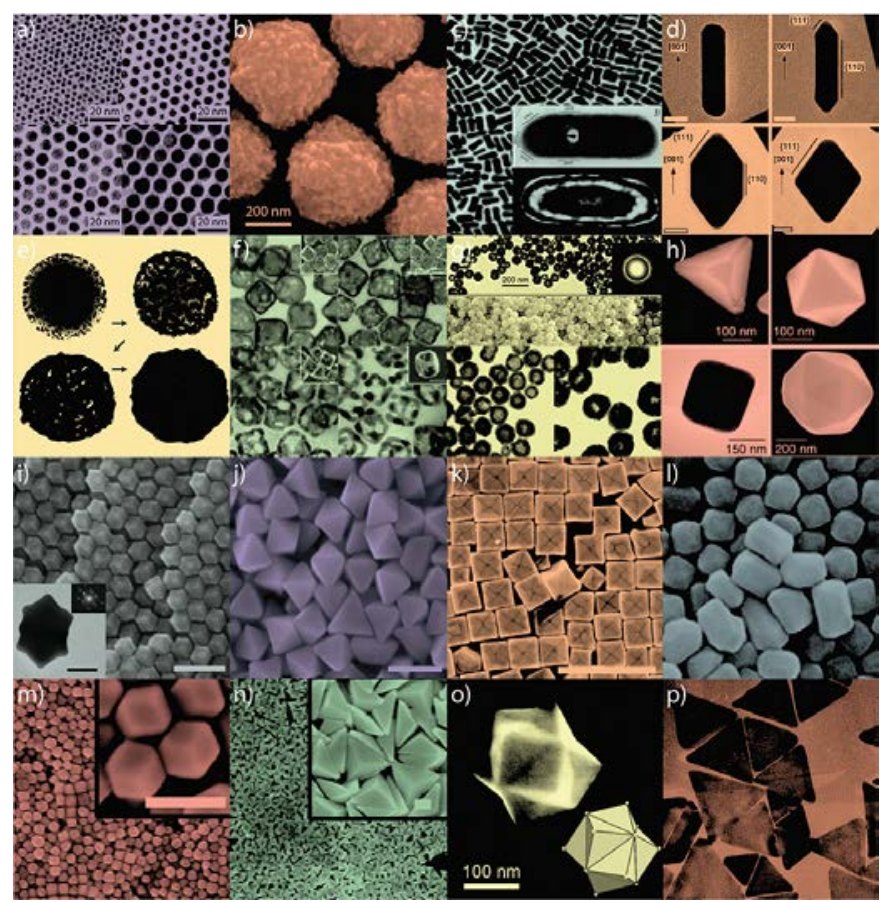

Figure 2. A summary of some of the many gold nanoparticle (AuNP) morphologies that can be accessed via conventional synthetic methodologies: small (a) and large (b) nanospheres, (c) nanorods, (d) sharpened nanorods, (e) nanoshells, (f) nanocages/frames, (g) hollow nanospheres, (h) tetrahedra/octahedra/cubes/icosahedra, (i) rhombic dodecahedra, (j) octahedra, (k) concave nanocubes, (I) tetrahexahedra, (m) rhombic dodecahedra, (n) obtuse triangular bipyramids, (o) trisoctahedra, and (p) nanoprisms. Reproduced with permission from ${ }^{187}$

We have already mentioned that a wide range of AuNPs shapes and sizes are accessible for siRNA delivery (Figure 2); however, the choice of the AuNP shape should not be taken lightly, because properties such as cellular internalization, biodistribution, siRNA loading capacity and optical properties can all vary markedly. For example, a comparison between gold nanorods and nanoprisms of similar size and LSPR band for photothermal therapy showed almost no cellular internalization in the case of gold nanorods while comparable gold nanoprisms with a similar surface coverage displayed a high internalization. ${ }^{55}$ Another interesting comparison was performed by Wang and collaborators, where they showed how gold nanorods internalize less than gold nanocages and nanohexapods in the breast cancer cell line MDA-MB-435. ${ }^{56}$ In this same report, they studied the biodistribution of these nanoparticles after intravenous injection in athymic nude mice with induced tumors and discovered that gold nanorods and nanohexapods accumulated in the tumors more efficiently than nanocages, making them more adequate candidates for anticancer treatment. Although shape and size of AuNP are important factors influencing cellular and tissue interactions, both factors can be altered after siRNA functionalization. For these reason, these studies comparing different AuNPs should be performed after siRNA functionalization like the one carried out recently by Yue et $a . .^{57}$ In this study, they observed much higher cellular uptake efficiency in U87 cells for $50 \mathrm{~nm}$ gold nanospheres and $40 \mathrm{~nm}$ nanostars compared to $13 \mathrm{~nm}$ spheres. Surprisingly, after 24 hours the larger particles $(40 \mathrm{~nm}$ stars and $50 \mathrm{~nm}$ spheres) had escaped from endosomes and were distributed throughout the cytoplasm while the $13 \mathrm{~nm}$ spheres remained in the endosomes, suggesting that larger nanoparticles were better candidates for siRNA delivery.

As previously mentioned, one of the main advantages of AuNPs as siRNA delivery agents is their unique optical properties. These optical properties result from coherent oscillations of conduction electrons on the metal surface due to excitation by electromagnetic radiation at a metal-dielectric interface, called surface plasmon resonance (SPR) effect. ${ }^{58}$ The frequency of the surface plasmon resonance depends on the metal, the refractive index of the media and the presence of other molecules in the surrounding environment. These surface plasmon resonance effect is called localized surface plasmon resonance effect (LSPR) when the electromagnetic wavelength is confined on a limited nanostructure. ${ }^{59}$ When the size of spherical AuNP changes, their LSPR bands displace slightly. However, in the case of anisotropic AuNPs such as nanorods, nanocages or nanoprisms, their optical properties change very dramatically depending on the aspect ratio (proportion between their different dimensions). ${ }^{60}$ This property can be harnessed for siRNA delivery applications using photothermal therapy, photothermal drug delivery or optoacoustic imaging, as described in section 3.3.

Although the synthesis of AuNPs of different shapes is now incredibly well documented in the literature (Figure 2), their use for siRNA delivery is surprisingly scarce. For in vivo siRNA delivery, gold nanospheres ${ }^{61}$ or nanorods ${ }^{62}$ are the most commonly employed variants, although recently there have been some interesting studies employing gold nanostars ${ }^{63}$ and gold nanoshells ${ }^{64}$ in mice. In the case of in vitro siRNA delivery studies, gold nanospheres, ${ }^{65}$ nanorods ${ }^{66}$ and nanoshells ${ }^{67}$ are the most frequently studied; although gold nanoclusters, ${ }^{68}$ dendritic nanoparticles, ${ }^{69}$ and nanoflowers ${ }^{70}$ have also been documented. All this information is summarized in Figure 3.

Another attractive approach is to use mixed metal nanoparticles made of gold and other hard materials in order to take advantage of the properties of both materials. By this way, siRNA has been delivered in different cells employing different engineered hybrid nanomaterials: magnetic-gold nanoparticles in order to confer magnetic properties and used also as magnetic resonance imaging contrast agents; ${ }^{71}$ silica-gold nanorods with higher siRNA loading capacity than bare gold nanorods ${ }^{72}$, core-shell bismuth-selenide nanoparticles to confer appropriate properties for Surface Enhanced Raman Spectroscopy (SERS) ${ }^{73}$ and gold-nickel nanorods that possessed 
two different material surfaces for controlled functionalization of different molecules by different strategies. ${ }^{74}$

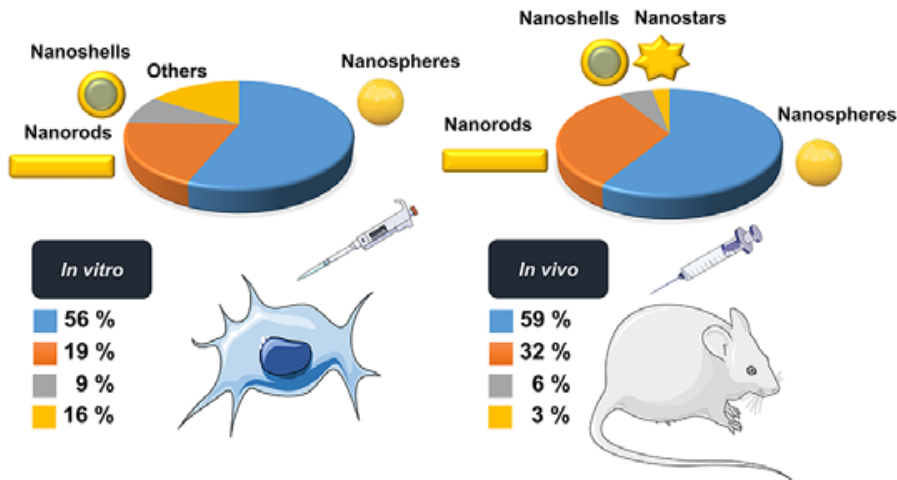

Figure 3. Frequency of utilization of different AuNP shapes employed for siRNA delivery from 2012 to present for in vitro (left) or in vivo (right) studies according to the search "gold nanoparticle siRNA" in Scopus and Web of Science databases, and verifying that the AuNPs have been employed for siRNA delivery. This figure was produced using some elements from Servier Medical Art PowerPoint image bank.

\subsection{Gold nanoparticle surface coatings}

It is clear that selecting the most appropriate AuNP is an important consideration for the final application, but by the same token, it is the chemical surface of the AuNP what determines many of the biointeractions and subsequent properties of the particles in cells and living systems and is therefore another crucial factor that must be considered. For this reason, AuNPs are usually coated with molecules that confer colloidal stability and improve the bioavailability of the particle. The nature and extent of AuNPs surface coating controls the interaction with all the components of the physiological medium, such as different proteins, ions, hydrophilic or hydrophobic molecules as well as with the other nanoparticles. The AuNP-medium interface determines NP stability and governs the properties of the particle, affecting different phenomena such as immune response, extravasation, cellular internalization or accumulation in a cell-type dependent manner. As an illustrative example, Liu et al. proved that AuNPs of different sizes possessing differently charged end groups in their surface internalized similarly in phagocytic RAW 264.7 cells, but positively charged nanoparticle uptake was increased in the case of non-phagocytic HepG2 cells, independently of their size. ${ }^{75}$

It is noteworthy that surface chemistry of nanomaterials not only influences their internalization, but can also affect their intracellular location and elimination. For these reasons a proper surface coverage is crucial for any AuNP biological use. In a biological medium, biomolecules (particularly proteins and lipids) tend to adsorb on the nanoparticle surface, forming an encapsulating complex around the nanoparticle most often referred to as the protein corona. ${ }^{76,77}$ The composition of protein corona varies greatly depending on the AuNP surface, ${ }^{78}$ although it can be also influenced by their size ${ }^{51}$ and shape. ${ }^{77}$ Differences in the protein corona have been shown to alter the cellular internalization pathways in a cell-type dependent manner. As an example, protein corona hampers the recognition of AuNPs by scavenger receptors but promotes the clathrin receptor-mediated recognition. ${ }^{51}$ Advances on the in situ analysis of protein corona interacting with nanoparticles will help in the near future to design surface coating on demand for each application. ${ }^{79}$

In order to minimize any non-desired effect of protein corona formation, such as changes in internalization pathways, aggregation or macrophages recognition, and to maximize the nanoparticle stability in biological media, different AuNP coating strategies can be employed. Although some approaches use the reducing agent required for the AuNP synthesis as a final stabilizer (e.g., citrate), the most interesting results are obtained when the coating is designed specifically for the desired application, especially when it can be used for subsequent functionalization with other molecules of interest, such as siRNA or targeting ligands. Most frequently, AuNP surfaces are stabilized with coordinating thiol groups where the most common coating agents include different types of polymers and surfactants, e.g. thiolated poly(ethylene glycol) (PEG), thiolated end-capped polystyrene (PS), poly(ethylenimine) (PEI), thiolate poly(vinyl pyridine) (PVP), polyamidoamine (PAMAM) dendrimers and cetyltrimethylammonium bromide (CTAB), among others. ${ }^{80}$ In the case of in vivo applications, the coating determines the blood half-life, the reticuloendothelial system avoidance and the delivery in the desired tissue. The length of the PEG chain has been shown to drastically affect and change AuNP blood half-life. ${ }^{81}$ Silica shell coatings represent another interesting kind of coating recurrent in AuNP bibliography and one that confers high stability to AuNPs when they are irradiated with a pulsed laser for optical applications. ${ }^{82}$ It can be employed to carry different drugs in cellular studies, providing a high internalization and cell viability; 83 moreover, silica coated AuNPs were used in the only successful clinical trial carried out in humans using AuNPs. ${ }^{84}$

In the case of siRNA delivery, different coatings have been successfully employed, the most common being thiolterminated polymers, ${ }^{85}$ layer-by-layer coatings made of different polymer layers ${ }^{86}$ or silica. ${ }^{66}$ For siRNA delivery the surface coating must not only provide an increased cellular internalization but also help the endosomal escape of the nanoparticle to the cytoplasm, where the siRNA action takes place. $\mathrm{pH}$-sensitive siRNA vehicles were employed by Liang and co-workers to liberate siRNA in the cytoplasm thanks to chargereversal action of different coating layers. ${ }^{87}$ Another common strategy consists of taking advantage of the 'proton-sponge effect' caused by cationic polymers that cause the disruption of endosomes due to osmotic swelling, as in the case of poly(allylamine hydrochloride) and siRNA multi-layered AuNPs. ${ }^{88}$ Other approaches include the use of amphiphilic bifurcated ligands to facilitate the permeation of AuNPs to the cytoplasm ${ }^{89}$ or the use of $\mathrm{pH}$-responsive DNA-conjugatedAuNPs carrying siRNA that aggregate inside endosomes helping their cytoplasmic release, as shown by TEM imaging. ${ }^{90}$ 
Despite the numerous studies on AuNPs for siRNA delivery, just a few have focused on the importance of the AuNP coating. In this respect, an interesting work was developed by Garg and co-workers, comparing three different polyelectrolytes (polyethyleneimine, citraconic anhydride modified poly (allylamine) hydrochloride and poly L-arginine) for layer-bylayer coating of AuNPs for siRNA delivery in BACE1 neuronal cells, demonstrating that the most efficient silencing was obtained with polyethyleneimine due to a higher transfection and loading capacity. ${ }^{91}$

Reich and co-workers employed another noteworthy coating strategy, where thiolated siRNA was employed as the AuNP coating but using different ratios of thiol-siRNA and biotin-functionalized thiol-siRNA. After that, the nanoparticles were incubated with streptavidin that bound specifically to biotin group and was used as a scaffold for subsequent linkage of biotin-TAT peptide. ${ }^{92}$ Dark Field imaging was used to show that the internalization of the AuNPs increased clearly with the fraction of thiol-siRNA-biotin employed (Figure 4).

A)
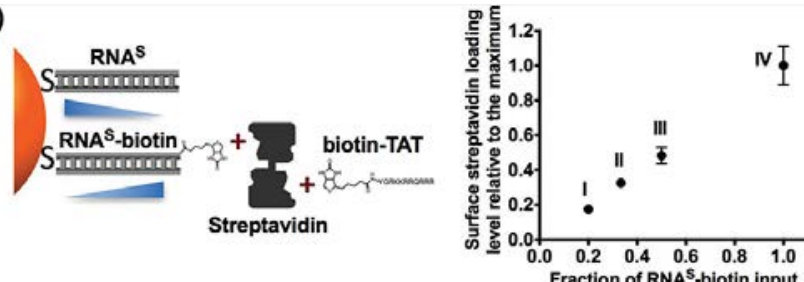

B)

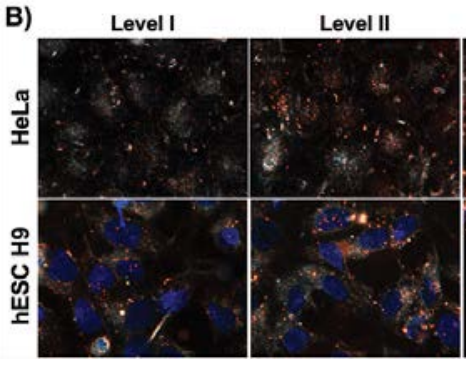
Level III

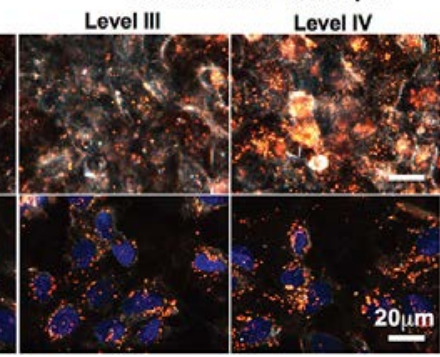

Figure 4. Example of the importance of AuNP coating in siRNA delivery. Hollow gold nanoshells were coated with increasing levels of biotin-modified RNAs to provide enhanced cellular internalization. A) Streptavidin interaction is strongly related with the ratio between siRNA-biotin and siRNA (levels I-IV) employed in the RNA assembly to the AuNP surface. B) Dark-field images of AuNPs (gold spots) with different levels of streptavidin coating internalized around nuclei (blue zones by Hoechst staining) in HeLa cells (top) and hESC H9 cells (bottom). Reproduced with permission from ${ }^{92}$

It should be noted that a proper surface coating not only provide the advantages listed for the siRNA delivery but also may permit the administration of the particle through new administration routes. For example, recently AuNPs carrying siRNA against Akt have been covered with glycol chitosantaurocholic acid in order to protect the siRNA from gastrointestinal degradation when administered orally. ${ }^{93}$ This coating also facilitated active transport through enterocytes and enhanced selective accumulation in colorectal liver metastasis in animal models, where the siRNA action took place causing cancer apoptosis and displayed enhanced tumor reduction with longer survival time for the mice.

\subsection{Gold nanoparticle siRNA functionalization strategies}

Since the first AuNP-mediated siRNA delivery was performed in $2006,{ }^{94}$ a long list of techniques have been employed to "functionalize" (i.e. associate or conjugate) AuNPs with siRNA. However, due to large variety of AuNP shapes, functionalization strategies, siRNA-targeted genes, cell lines and analytical techniques used to detect the siRNA activity, finding a general conclusion concerning the most suitable siRNA functionalization technique for any given application poses a significant challenge. What follows represents a summary of the most common siRNA functionalization techniques (Figure 5), paying special attention to their potential use in a clinical setting.

RNA monolayers can be created by linking siRNAs directly to the AuNP surface via Au-thiol coordination bonds (Figure 5A) or to the polymeric surface coating of the AuNP through covalent bonds (Figure 5B), e.g. amide, by means of a crosslinker. The use of electrostatic interactions (Figure $5 \mathrm{C}$ ) represents a less specific yet highly effective means of functionalizing AuNPs with siRNA. A different approach utilizes AuNP functionalized with DNA to provide ssDNA-specific sequence hybridization with ssRNA (Figure 5D) by hydrogen bonding. In the case of the direct Authiol coordination bonding mode (Figure 5A), synthetic thiolterminated siRNAs are employed to interact directly with the gold surface, producing a stable Au-S bond at physiological conditions. This technique was first reported in 1996 by Mirkin et al. to conjugate DNA to AuNPs. ${ }^{95}$ When thiol capped siRNAs are employed for AuNPs functionalization they can saturate the entire AuNP surface forming an RNA monolayer surrounding the nanoparticle ${ }^{67}$ (see Figure 5A.1). This functionalization technique was employed to evaluate RNA interference by AuNP delivery of siRNA, single-stranded RNA (ssRNA) and singlestranded DNA, providing similar successful results in the three cases. ${ }^{96}$ However, a better control of nanoparticle surface is obtained and a decrease in non-specific protein adsorption is observed when a mixed monolayer is obtained using a combination of thiol-capped siRNA and thiol-capped polymers (Figure 5A.2), for example PEG. ${ }^{97}$ In addition, when the number of ssRNA per nanoparticle can be controlled, two complementary ssRNAs can be linked to different nanoparticles and hybridized as building blocks to form nano-assemblies with controlled geometries. ${ }^{98}$ However, some limitations should also be considered, for example Barnaby et al. demonstrated how serum nucleases degraded siRNA bound to the nanoparticle in a sequence-dependent manner. ${ }^{99}$ In the same study, the authors showed how nucleases splice the siRNA in a different position depending on whether they are linked to the nanoparticle or are free, highlighting the influence of the AuNP when choosing the siRNA sequence. Thus, the scientific literature can be used as a guideline for selecting the most active siRNA sequences and some algorithms have been developed to predict the hybridization thermodynamics of siRNA to a complementary target mRNA, ${ }^{100}$ but the selection of the siRNA should be made carefully. 


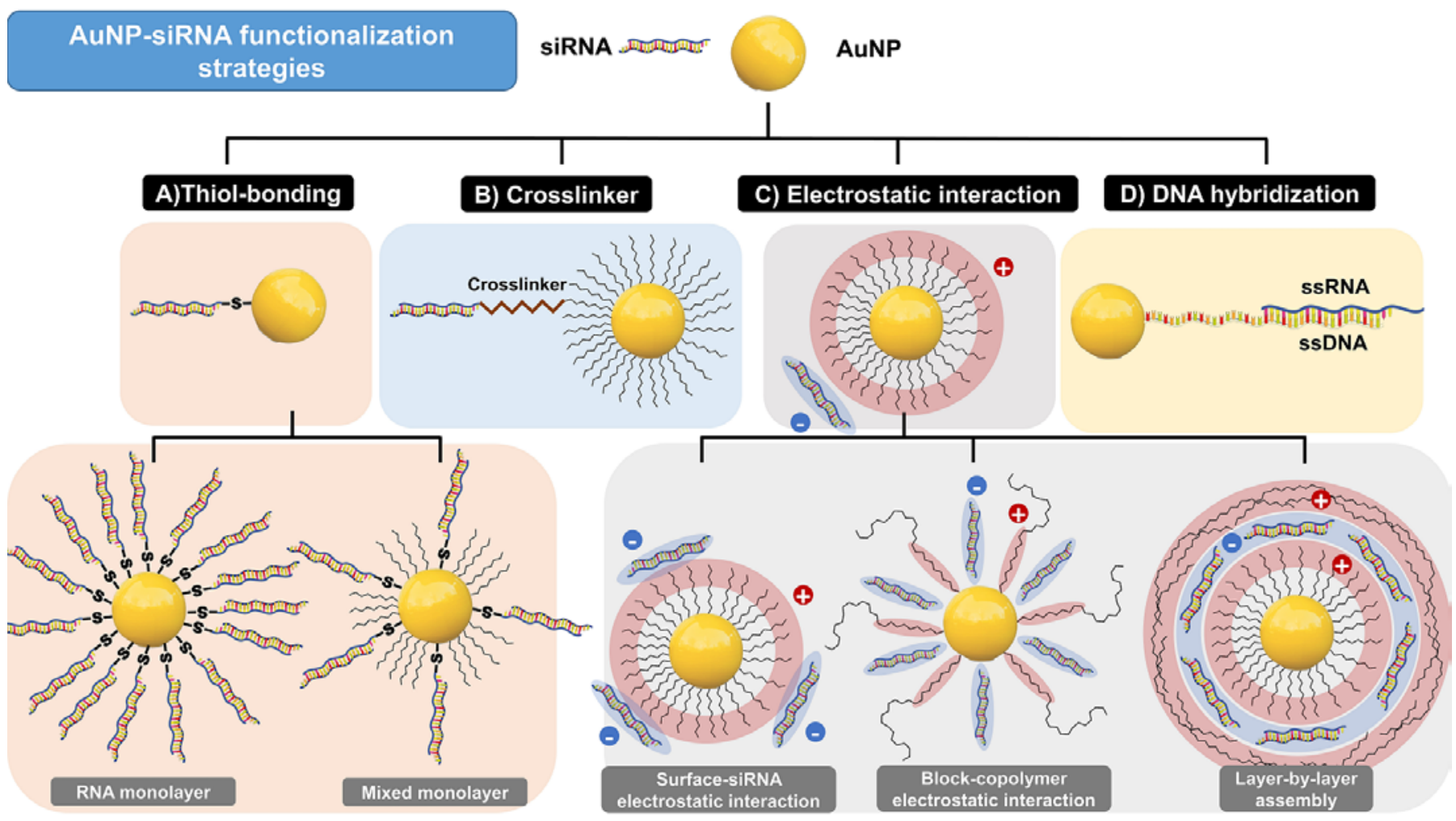

Figure 5. Most common siRNA functionalization strategies for AuNPs based on electrostatic association, covalent/coordination bonding and hydrogen bonding. siRNA can be directly linked to the gold surface by thiol-bonding (A) to form a RNA monolayer (A.1) or a mixed monolayer with other thiolated molecules (A.2). Covalent bonding between siRNA and AuNP coating can be obtained by the employment of a crosslinker (B). Electrostatic interaction (C) takes advantage of negative charge of siRNA to interact with different positively charged parts of the AuNPs, including the surface of AuNP coating (C.1), the inner part of block copolymers in the AuNP coating (C.2) or different positive layers surrounding the nanoparticle in a layer-by-layer assembly (C.3). Specific sequence hybridization can be obtained using ssDNA linked to AuNP complementary to ssRNA by hydrogen bonding (D). This figure was produced using some elements from Servier Medical Art PowerPoint image bank.

Another often reported siRNA functionalization technique consists of simple electrostatic interactions, which use the intrinsic negative charge of siRNA to attach to a positively charged molecule (Figure $5 \mathrm{C}$ ). As a result, different positively charged molecules can be anchored to the nanoparticle, including poly(L-lysine), ${ }^{101}$ chitosan, ${ }^{102}$ poly(diallyldimethylammoniumchloride), ${ }^{103}$ poly(2(dimethylamino) ethyl methacrylate-2-hydroxyethyl methacrylate), ${ }^{104}$ polyethyleneimine, ${ }^{105}$ protamine, 65 (16mercaptohexadecyl) trimethylammonium bromide, ${ }^{89}$ polyamine, ${ }^{106}$ cationic phospholipids, ${ }^{107}$ poly(allylamine hydrochloride), ${ }^{108}$ bovine serum albumin ${ }^{70}$ or even metallic cations, ${ }^{109}$ among others. Although electrostatic binding of siRNA can be performed using AuNPs with a positively charged surface coating ${ }^{110}$ (Figure 5C.1), using this approach the siRNA remains exposed in the surface and cationic nanoparticles have demonstrated serious toxicity problems in some cases. ${ }^{111}$ To overcome this problem, different strategies have been investigated, such as the use of AuNPs covered with block copolymers with a positively charged inner part that interacts with the siRNA and an external part with low toxicity (Figure 5C.2). Some studies have included poly(ethylene glycol)-bpoly(L-lysine) ${ }^{112}$ and poly(ethylene glycol)-polyarginine as block copolymers. $^{113}$

Another widely utilized strategy consists of a layer-by-layer deposition surrounding the AuNP (Figure 5C.3). The layer-by- layer fabrication method utilizes the interaction of oppositely charged polyelectrolytes to generate multiple thin films. ${ }^{114}$ In the case of siRNA functionalized AuNPs, by this method multiple layers of RNA can be sandwiched between biodegradable polymers, ${ }^{115}$ allowing a sequential release of the genetic materials. Such nanoparticles have demonstrated their resistance to nuclease degradation ${ }^{116}$ and have been employed for siRNA delivery in vivo where a significant interference effect was maintained over a period of 20 days. ${ }^{117}$

A direct comparison of covalent vs. electrostatic siRNA functionalization was performed by $\mathrm{M}$. de la Fuente and coworkers. ${ }^{61}$ In this work AuNPs with different PEG coatings were analysed as nanocarriers for c-myc siRNA whereby the siRNA was linked to the AuNP either by thiol-Au siRNA functionalization or electrostatic interaction using an azideterminated PEG. Further, a pyramidal functional screening strategy was employed to probe the nine types of different AuNPs for RNA interference, whereby the nanoparticle variants were first tested in a mammalian cell model, before proceeding to two separate in vivo models: first in Hydra vulgaris and finally in mice. At each stage of the process the most effective nanoparticles were selected for testing in the higher order model (Figure 6), demonstrating that thiol-bonding of siRNA worked better than ionic interaction in the studied system. Using three biological models of increasing complexity the 
authors reduced time and costs, avoiding unnecessary vertebrate testing.

Other functionalization techniques that did not imply thiol bonds or electrostatic interactions have also been performed. For example, Altinkaya and co-workers utilized PEG-coated
Recently, a similar approach has been reported using siRNA specific binding proteins anchored to the AuNP. ${ }^{121}$

There have also been some recent examples of siRNAs coencapsulated with AuNPs in different types of nano- and microcapsules. ${ }^{122-124}$ It should be noted that molecular
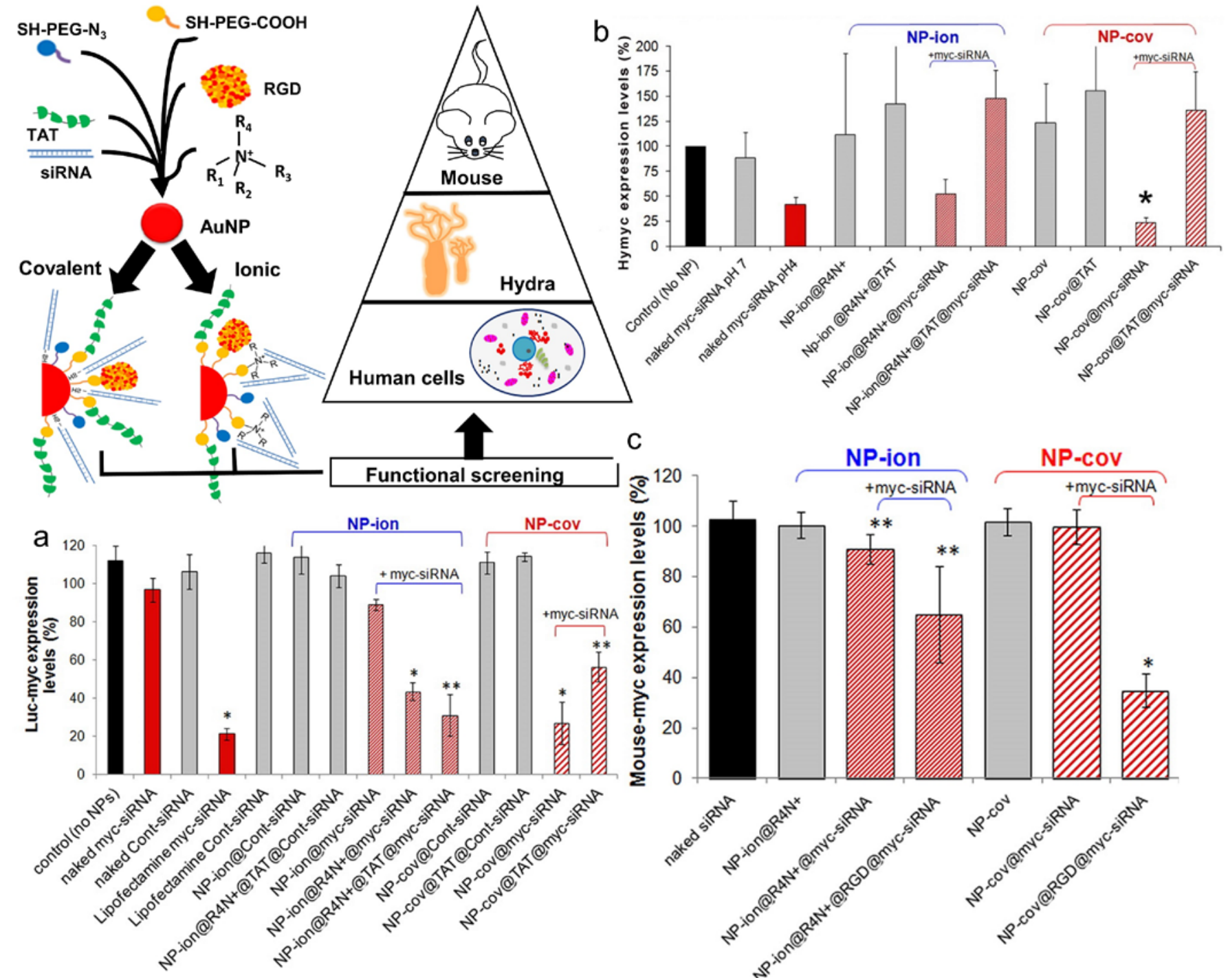

Figure 6. In vitro and in vivo gene silencing using covalent or ionic siRNA functionalization approaches based on multi-functional AuNPs covered with PEG, cell penetration peptides and adhesion peptides. The study employed a hierarchical scheme using three biological systems of increasing complexity: cultured cells (HeLa), freshwater polyp (Hydra vulgaris), and mouse (C57BL/6j) to select the most effective engineered AuNP and test it in the higher order level. a) RNAi efficiency against the fusion protein Renilla luciferase-myc in HeLa cells. Data marked with asterisks are statistically significant relative to the corresponding NP-ion/cov with control siRNA. Sample t test (**, P e 0.0001; *, P e 0.001). b) Hymyc RNAi in Hydra vulgaris study by qRT-PCR. Sample t test (*, P e 0.005). c) c-myc RNAi in mouse, analyzing RNA extracted from lung tissue by qRT-PCR. Sample $t$ test $(*, P$ e $0.001 ; * *, P$ e 0.01$)$. Adapted with permission from ${ }^{61}$.

nanoparticles with covalently attached siRNA using a crosslinker (Figure 5B) (concretely N-succinimidyl-3-(2pyridyldithio)-propionate). Thereafter the siRNA@AuNP core was covered by a pentablock copolymer via electrostatic interactions. Importantly, the degradation by nucleases was highly dependent on the copolymer composition. ${ }^{118}$

Another approach is the specific hybridization of the ssRNA with complementary ssDNA molecules through hydrogen bonding (Figure 5D). By this method, several siRNAs can be attached to a DNA molecule in a specific manner ${ }^{119}$ or a complex DNA assembling can be used to control the siRNA release. ${ }^{120}$ dynamics simulations are doing a great deal to assist in siRNA functionalization by simulating size and charge-dependent siRNA complexation with gold nanoclusters ${ }^{125}$ and assembly and release of siRNA from polymer/AuNPs polyplexes. ${ }^{126}$ Theoretical studies such as these could help to design siRNA delivery vehicles in the near future.

Once the functionalization has been performed it is of course essential to evaluate the amount and functionality of siRNA that has been conjugated to the AuNP. Several different strategies can be employed to quantify the siRNA that has been linked to the particle. In cases where siRNA can be easily 
released from the nanoparticle (e.g. using DTT for thiol-bond reduction), 118 it can then be quantified by agarose gel or spectroscopic absorbance measurement. ${ }^{87}$ Other methods include the labeling of siRNA with a fluorophore before the release and their subsequent quantification using a fluorimeter ${ }^{89}$ or the use of commercial detection kits. ${ }^{118}$ In other cases, these same measurements can be performed with the siRNA collected from the reaction supernatant solutions (i.e. siRNA not linked during the conjugation process) inferring that any siRNA that is not identified in the supernatant has been linked to the AuNP. To analyze the cellular internalization and endosomal escape some authors employ fluorophore-labelled siRNA. ${ }^{87,108}$

In order to evaluate the functionality many studies employ siRNA targeting a reporter gene, such as GFP127 or luciferase. ${ }^{118}$ siRNA functionality for other genes can be measured at the mRNA level by RT-PCR or at the protein level using western-blot when the corresponding antibody is available ${ }^{122}$ or ELISA. ${ }^{108}$

\section{Approaches to improve siRNA delivery efficacy and clinical interest}

To date, the most widespread use of AuNPs carrying siRNA in the literature has been as a tool for targeted siRNA release in anticancer applications. Concretely, these organic-inorganic hybrid nanoparticles have demonstrated an ability to reduce tumor volume, ${ }^{128}$ to silence chemotherapeutic resistance, ${ }^{87,124}$ to improve radiosensitivity, ${ }^{103}$ to decrease cell migration and cell invasion, 108 often in combination with photothermal therapy. ${ }^{129}$ However, siRNA-AuNP complexes have also been utilized, to a lesser extent, in the study of opiate addiction, ${ }^{130}$ the study of topical delivery, ${ }^{131}$ as an antiviral for Dengue virus infection treatment, ${ }^{116}$ for gene expression analysis, ${ }^{132}$ as transmission electron microscopy markers, ${ }^{123}$ for X-ray contrast agents, ${ }^{70}$ in HIV infection studies, ${ }^{133}$ for psoriasis treatment, ${ }^{134}$ for stem cell differentiation, ${ }^{135}$ to control photonic gene circuits $^{107}$ as well as for chronic pancreatitis, ${ }^{136}$ to improve wound healing in diabetic mice ${ }^{137}$ and to evaluate efficacy of non-classic siRNA variants. ${ }^{138}$

Despite the vast amount of biotechnological applications that have been explored using AuNPs they also present several drawbacks that should be considered before continuing developing their use as siRNA carriers; in particular when compared with liposomes, which are currently the most advanced and safest carrier for siRNA. Liposomes and lipid nanoparticles have shown promising results in this field ${ }^{139}$ and continue to undergo development for new siRNA delivery applications. ${ }^{140-142}$ Their physicochemical properties readily lend them to siRNA delivery and show high efficacy, safety at the studied doses and limited or no side-effects, as demonstrated by the high number liposomal delivery systems in preclinical trials and in particular the recent approval of lipidbased medicine Patisiran (see Section 1). By comparison, AuNPs present several limitations that should be overcome before their clinical employment. The main problem of AuNPs and other metal-based nanoparticles is of course their long-term accumulation in vivo as a result of their low biodegradabillity. ${ }^{143}$ It has been described how the polymeric coating of AuNPs can facilitate a more rapid degradation, earlier than the bare metallic core, which will tend to accumulate in organs instead of being excreted. ${ }^{144}$ This is particularly problematic in the case of larger AuNPs ${ }^{53}$. Although several studies show accumulation of AuNPs in tissues and organs, ${ }^{54,145}$ it is not clear if the longterm effect could produce a real danger to the health of the patient. For this reason, a conscientious effort should be made by researchers working with AuNPs for biomedical applications to address this uncertainty. Other problems related with AuNPs are immunogenicity, ${ }^{46}$ instability and toxicity ${ }^{146}$, associated with ROS generation, formation of apoptotic body and impairment of mitochondrial activity ${ }^{147}$. However these issues can certainly be reduced - as seen in Section 2.2 - by a chemical control of the surface coating of the AuNPs, correct for the desired application or route of administration.

Regardless of the end application, the aforementioned drawbacks of AuNPs can be improved using several strategies, namely targeted delivery of the material, co-delivery of other drugs, harnessing the optical properties of the AuNPs and by encapsulating the AuNP with the siRNA. In addition these strategies can also be employed to increase the efficacy, specificity and clinical interest of AuNP-mediated siRNA delivery. The following sections of this review offer an overview of these key strategies by providing details of the most recent reports from the literature.

\subsection{Targeted delivery}

The objective of targeted delivery consists of the predominant accumulation of the desired drug at the zone of interest. When talking about systemic delivery, targeted delivery includes reaching the desired tissue and entering inside the cytoplasm of the target cell. ${ }^{148}$ In many anticancer applications nanomaterials reach the tumor due to the enhanced permeability and retention (EPR) effect, which consists of the accumulation of blood circulating nanoparticles in malignant tissue penetrating the highly permeable discontinuous endothelia. ${ }^{18}$ However, this approach commonly leads to the accumulation of the nanomaterials in the cells of the reticuloendothelial system (RES) before they can reach their 


\begin{tabular}{|c|c|c|c|c|}
\hline Authors & $\begin{array}{c}\text { Year of } \\
\text { publication }\end{array}$ & $\begin{array}{l}\text { Targeted delivery } \\
\text { molecule linked to } \\
\text { the AuNP }\end{array}$ & $\begin{array}{l}\text { Targeted receptor of the } \\
\text { delivery }\end{array}$ & $\begin{array}{l}\text { Co-delivery of other } \\
\text { drugs }\end{array}$ \\
\hline J. Conde et al. ${ }^{61}$ & 2012 & TAT peptide & $\begin{array}{c}\text { Not clear (different } \\
\text { mechanisms have been } \\
\text { proposed) }\end{array}$ & \\
\hline M. Mitra et al. ${ }^{149}$ & 2013 & $\begin{array}{l}\text { EpCAM monoclonal } \\
\text { antibody }\end{array}$ & $\begin{array}{c}\text { EpCAM (epithelial cell adhesion } \\
\text { molecule) }\end{array}$ & \\
\hline X. Huang et al. ${ }^{67}$ & 2014 & TAT peptide & $\begin{array}{c}\text { Not clear (different } \\
\text { mechanisms have been } \\
\text { proposed) }\end{array}$ & \\
\hline S. Acharya et al. ${ }^{150}$ & 2014 & $\begin{array}{l}\text { KDEL (Lys-Asp-Glu- } \\
\text { Leu) peptide }\end{array}$ & $\begin{array}{l}\text { KDELR (KDEL protein retention } \\
\text { receptor) }\end{array}$ & \\
\hline J.H. Choi et al. ${ }^{122}$ & 2015 & $\begin{array}{c}\text { Antibody against } \\
\text { HER-2 }\end{array}$ & HER-2 & \\
\hline P. Zhang et al. ${ }^{120}$ & 2016 & $\begin{array}{c}\text { RGD peptide } \\
\text { (arginylglycylaspartic } \\
\text { acid) }\end{array}$ & Integrins & Doxorubicin \\
\hline J. Conde et al. ${ }^{129}$ & 2016 & $\begin{array}{l}\text { Influenza } \\
\text { haemagglutinin } \\
\text { (HA1) Peptide }\end{array}$ & $\begin{array}{l}\text { HA receptor in endosomal } \\
\text { membranes }\end{array}$ & Avastin (VEGF inhibitor) \\
\hline L. Gamrad et al. ${ }^{151}$ & 2016 & $\begin{array}{l}\text { Nuclear Localization } \\
\text { Signal (NLS) peptide }\end{array}$ & Importin $\alpha$ & \\
\hline $\begin{array}{l}\text { K.A. Fitzgerald et } \\
\text { al. }^{152}\end{array}$ & 2016 & Anisamide & Sigma receptor & \\
\hline L. Fan et al. 128 & 2016 & $\begin{array}{l}\text { Monoclonal antibody } \\
\text { against FAT1 }\end{array}$ & Protocadherin Fat 1 & HCPT and Doxorubicin \\
\hline S. Wang et al. ${ }^{63}$ & 2016 & Hyaluronic acid & CD44 receptor & \\
\hline N. Li et al. ${ }^{153}$ & 2017 & $\begin{array}{l}\text { Nuclear Localization } \\
\text { Signal (NLS) peptide }\end{array}$ & Importin $\alpha$ & \\
\hline H. Zhu et al. ${ }^{154}$ & 2017 & 2-deoxyglucose & Glucose transporter 1 (GLUT1) & \\
\hline
\end{tabular}


target. To improve the targeting effect, an active targeting approach involving the conjugation of targeting ligands to the nanoparticle that interacts specifically with molecules in the target cells can be employed. In the case of AuNPs, the conjugation of different cell penetrating peptides to the particle can facilitate cytoplasmic entry in the desired tissues. These cell penetrating peptides are small sequences of amino acids derived from different natural proteins, formed by fusion of other cell-penetrating peptides or completely synthetic. The exact entry mechanism by which AuNP are internalized in the cell and released to the cytoplasm thanks to this peptides is not clear, although different endocytosis and endosomal escape models have been proposed. ${ }^{155}$ For example Kannan and coworkers showed how AuNPs functionalized with bombesin peptide for promoting interaction with gastrin-releasing peptide receptor exhibited a completely different biodistribution from their non-functionalized counterparts after intraperitoneal injection. Liver accumulation was decreased more than twice but the accumulation in organs that express the receptor was increased. ${ }^{156}$

Different cell penetrating peptides have also been utilized for siRNA-functionalized AuNP delivery, including peptides with the motif arginylglycylaspartic acid (RGD) that is recognized by integrins, ${ }^{120}$ T-complex protein 1 subunit alpha (TCP-1) peptide that targets colorectal cancer cells and influenza haemagglutinin (HA1) peptide (a fusogenic peptide that destabilizes the endosomal membrane), ${ }^{129}$ the transactivator of transcription (TAT) peptide that promotes endocitosis, 67 peptides with the sequence Lys-Asp-Glu-Leu (KDEL) that promotes localization in the endoplasmic reticulum ${ }^{150}$ or peptides with the nuclear localization signal (NLS) to be imported into the cell nucleus. ${ }^{151}$ The importance of employing RGD in AuNP-mediated siRNA delivery against c-myc by intratracheal administration has been demonstrated to cause a $65 \%$ downregulation of c-myc observed by qRT-PCR, as opposed to no significant interference recorded for similar NPS without RGD. ${ }^{61}$ Another surprising work has demonstrated that when AuNPs with siRNA were functionalized with NLS peptide they were translocated to the nucleus and maintained their silencing effect in three different cell lines for long-term periods of more than 30 days instead of 2-3 days for their counterparts without NLS peptide. ${ }^{153}$

Other ligand molecules can be used to target AuNP to cells that express determined surface receptors, such as small molecules as folic acid or galactose, hormones and antibodies. ${ }^{157}$ In this line, cell studies have been performed using siRNA-conjugated AuNPs with anisamide to target sigma receptor ${ }^{152}$ or with 2 -deoxyglucose, ${ }^{154}$ a glucose analogue that is recognized by glucose transporter 1 (GLUT1), a vital prognostic indicator of tumorigenesis. Antibodies have also been recurrently employed for siRNA-AuNPs targeting and several studies have been published employing epithelial cell adhesion molecule monoclonal antibody, ${ }^{149}$ FAT1 antigen antibody ${ }^{128}$ and anti-HER-2 antibodies. ${ }^{122}$ An interesting report was published recently by Lu and co-workers, whereby AuNPs functionalized with siRNA via a layer-by-layer method with an external layer of hyaluronic acid improved their CD44-targeting ability and was verified using flow cytometry, confocal microscopy imaging and competitive binding analysis in different cell lines. Further, these particles were used to selectively sensitize tumors expressing CD44 receptor to photothermal treatment in an in vivo mouse model. ${ }^{63}$ Other innovative strategies have been developed to increase cellular internalization, for example Chen and colleagues employed ultrasound-propelled siRNA-DNA-gold nanowires to facilitate the cell entry in different cell lines, ${ }^{119}$ showing that they can dramatically accelerate the mRNA silencing compared with static nanowires. This strategy could be interesting in the future to increase local internalization in in vivo delivery and also when the target cells can be extracted from the body, as long as they resist the treatment. Another interesting approach using iontophoretic topical administration of AuNS-siRNA by electric field application was employed recently for melanoma cancer suppression showing similar results to intratumoral administration. ${ }^{158}$

\subsection{Co-delivery of other molecules}

One of the main advantages of nanomaterial-based delivery vectors is that they offer the possibility to direct different drugs and biomolecules using the same carrier, a strategy usually called co-delivery. AuNPs act as scaffolds and can be functionalized with almost any desired compound, including small molecules such as drugs, vitamins, lipids, sugars, peptides, fluorophores as well as larger biomolecules like nucleic acids (DNA and/or RNA), antibodies and cell signaling proteins. ${ }^{159} \mathrm{Co}-$ delivery strategies pave the way for a wider application of siRNA in future clinical treatments due to the sheer number of compounds that can be delivered together with siRNA in order to produce a synergistic effect.

The engineering of AuNPs to obtain multi-functional carriers requires different functionalization techniques in order to control the interaction of each molecule through step-wise processes. For example, AuNPs can be coated with a polymer with different chemical end-groups that permit the functionalization of each of these groups with different molecules via different chemical conjugation steps. ${ }^{61}$ Another strategy is the use of different surface coating molecules; where each one is functionalized previously with a different compound in order to form a complete coating with all the molecules together, for example using a block copolymer as coating agent with an inner part that interacts with siRNA protecting it and an outer part where the targeting ligand (octreotide) is linked and a methyl thioglycolate as the other coating agent to provide a $\mathrm{pH}$-labile hydrazone linkage of doxorubicin to enable $\mathrm{pH}$ controlled drug release. ${ }^{113} \mathrm{~A}$ recurrent alternative is the use of layer-by-layer functionalization technique, to locate different compounds in each layer. ${ }^{136,160}$ However, one highly versatile approach was proposed by $\mathrm{Oh}$ and co-workers. ${ }^{74}$ In this work, the authors employed a synthetic route for a two-component nanorod complex by electro-deposition, obtaining rods clearly characterized half of $\mathrm{Ni}$ and half of $\mathrm{Au}$. The presence of different 
metal surfaces permit the union of a variety of molecules - in this case siRNA and a fluorophore - using different functionalization techniques for each metal surface.

Different types of nanocarrier, each one functionalized with different (bio)molecules of interest can be also applied together to obtain a synergistic effect. One nice example of this approach was employed by Conde et al., using a hydrogel patch to deliver gold nanorods functionalized with avastin (a Vascular Endothelial Growth Factor (VEGF) inhibitor) and spherical gold nanoparticles with siRNA. ${ }^{129}$ Nevertheless, probably the most complex and advanced work of co-delivery concerning AuNPs with siRNA has been carried out by Jin and colleagues. ${ }^{128}$ In this paper, $\mathrm{SiO}_{2}$-Au nanoparticles are used as a complex vehicle for sequential drug delivery of several chemotherapeutics and siRNA with antitumor efficacy (Figure 7). This system is composed by an inner $\mathrm{SiO}_{2}$ nanoparticle used for encapsulating 10-hydroxycamptothecin (a DNA topoisomerase I inhibitor) and for adsorbing doxorubicin. The inner $\mathrm{SiO}_{2}$ nanoparticle is covered by several small AuNPs linked by electrostatic interactions forming a complex system of $50 \mathrm{~nm}$ diameter. These AuNPs also are functionalized with siRNA against B-cell lymphoma 2 protein (Bcl-2), an important anti-apoptotic protein in cancer, and antibodies against FAT1 antigen, a protein expressed in the cell surface of the target cells. After demonstrating that the system interacted with cells expressing FAT1 antigen, its cellular internalization and its endosomal escape, the authors studied the GSH-mediated siRNA release that occurs quite fast in less than 2 hours. They also showed how doxorubicin release in the cytoplasm took around 15 hours while 10-hydroxycamptothecin took around 30 hours. Finally, they studied the efficacy of $\mathrm{SiO}_{2}$-Au sequential drug delivery system by intravenous injection in a xenograft mouse model, showing a remarkable anticancer effect by delaying tumor growth that in the case of the most complex nanoparticles produced the tumor weight decreased 400 -fold. They did not report any noteworthy decrease in the weight of the mice, suggesting that this nanocomplex did not display a significant toxicity.

Despite being applicable to a variety of diseases and conditions, until now most of the research on AuNP-based siRNA co-delivery has been directed to cancer treatment. Doxorubicin is one of the most often employed antitumor agents that has been co-delivered with siRNA. ${ }^{66,120}$ Other studies include the use of multilamellar gold niosomes encapsulating thymoquinone and siRNA to overcome Akt induced resistance (one of the major mechanisms of chemoterapautic resistance in cancer cells due to the key role of protein Akt in cellular survival pathways) in breast cancer, ${ }^{124}$ Rap2b siRNA in order to improve the efficiency of the anticancer drug adriamycin, ${ }^{161}$ imatinib mesylate in order to improve STAT3 siRNA activity against melanoma, ${ }^{158}$ captopril and siRNA in antiangiogenesis breast cancer therapy ${ }^{162}$ or docetaxel and siRNA AuNP co-delivery for metastatic breast cancer. ${ }^{163}$ Another application of co-delivery is devoted to improve siRNA interference efficiency mediated by AuNPs, as it is the case of hydroxychloroquine that has been employed to enhance endosomal escape of gold nanoparticles carrying siRNA. ${ }^{164}$ DNA is one of the biomolecules that has also been co-delivered with siRNA. ${ }^{165}$ In this way, siRNA can be used to decrease the expression of specific proteins while plasmid DNA can be used to overexpress both exogenous and endogenous proteins. ${ }^{166}$ This approach has also been studied using Interleukin 10 (IL-10)

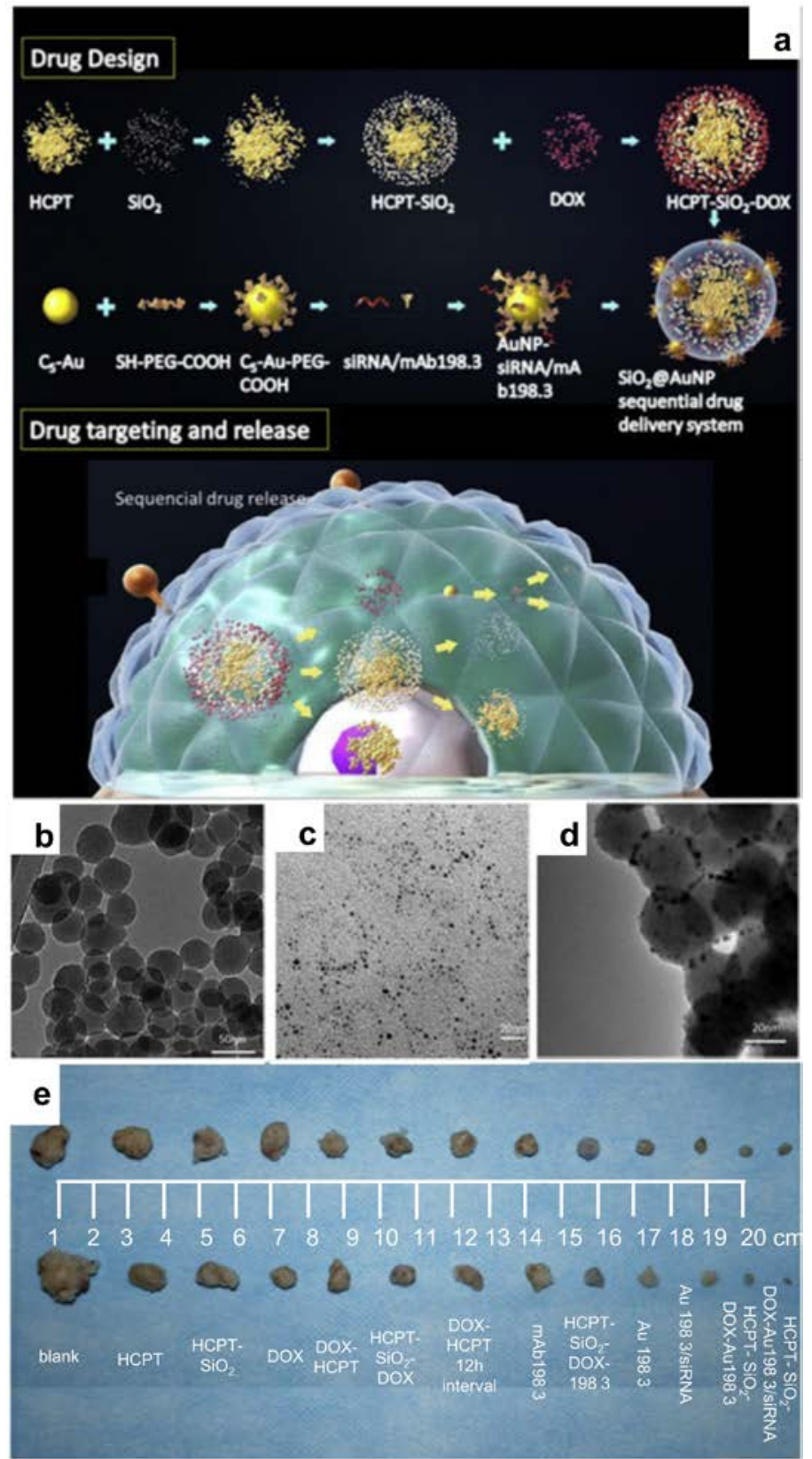

Figure 7. a) Illustrative scheme representing the synthesis of the silica and AuNP delivery system and the drugs and siRNAs sequential release in the cancer cell cytoplasm. The morphology and size of NPs were characterized by TEM imaging of (b) silica nanoparticles with HCPT and doxorubicin (c) AuNPs carrying siRNA and (d) silica and AuNP complete delivery system. e) Antitumor effect of each of the sequential components employed in silica and AuNP siRNA delivery on nude mice bearing Colo-205 cells subcutaneously, showing dissected tumor tissues from the nude mice. Reproduced with permission from ${ }^{128}$

plasmid DNA and Transforming Growth Factor $\beta$ (TGF- $\beta$ ) siRNA AuNPs to treat chronic pancreatitis. ${ }^{136}$ 


\subsection{Capitalizing on the optical properties of gold nanoparticles}

The unique optical properties of AuNPs depend mainly from the LSPR effect (see section 2.1) and by harnessing these optical properties, AuNPs have been studied for a wide variety of applications from drug delivery ${ }^{167}$ and biosensing 168,169 to optoacoustic imaging ${ }^{170}$ and photothermal therapy. ${ }^{171}$ In fact, the only completed clinical trial using AuNPs registered in the U.S. National Institutes of Health employed photothermal treatment applying laser at near-infra-red (NIR) wavelength in order to produce a temperature increase due to the interaction between laser light and AuNPs to reduce atheroma volume in coronary artery disease patients. ${ }^{84}$ In this clinical trial, involving 180 patients, silica-gold nanoparticles were administrated using stem cells in a surgically implanted patch or by intracoronary infusion of stem cells carrying iron-bearing silica-gold nanoparticles. After that the nanoparticles were irradiated by percutaneous transcatheter intravascular or out-of-body transcutaneous intercostal NIR laser irradiation, achieving a total atheroma volume reduction of $38 \%$. Although AuNPs have also been employed for laser-induced transient membrane perforation that facilitates siRNA cellular internalization, 172,173 the most interesting results are obtained when the irradiation is performed using AuNP functionalized with siRNA since the AuNP can be used as a dual-active delivery and release carrier.

Laser-triggered release of siRNA from AuNPs has been shown to increase RNA interference. ${ }^{110}$ In order to understand the mechanism by which AuNPs release siRNA under laser irradiation, an innovative study was carried out by Day and coworkers showing that pulsed laser irradiation release is a temperature independent process more efficient than continuous wave irradiation ${ }^{174}$. Laser-controlled siRNA release from AuNPs also shows potential as a precise strategy for controlled release. In this line, Lee and colleagues employed siRNA-conjugated Au nanorods ('nanoantennas') to obtain precise optical control for the reconfiguration of gene circuits in living cells. ${ }^{107}$ In this study, two different Au nanorods with aspect ratio of 2.5 and 4.0 were used for the controlled release of siRNA when irradiated with $660 \mathrm{~nm}$ and $785 \mathrm{~nm}$ lasers, respectively. Using this photothermal release system the researchers were able to control a gene circuit to produce a desired protein by laser irradiation, switching the circuit on with one laser and off with the other.

Optoacoustic imaging has also helped to demonstrate the utility of siRNA-AuNPs. When this imaging technique is used with AuNPs, light pulses provoked the thermoelastic expansion of the tissues where AuNPs are located producing ultrasound signals that are collected and used to form an image. Although this imaging technique is not as precise as others nanomaterialbased methods, 175 one of the advantages of optoacoustic imaging is that it can be combined with photothermal therapy using the same AuNP. ${ }^{170}$ For example, Taruttis et al., employed a liposome-gold nanorod nanocarrier for siRNA for multispectral optoacoustic tomography (MSOT) in 4T1 and HT29 tumor models and delivered siRNA against PLK1 to cause apoptosis of tumor cells. ${ }^{176}$ Irradiation of hollow gold nanoshells with NIR light have also been employed to produce RNAi in human embryonic stem cells. ${ }^{177}$

Although several interesting studies on the effect of siRNA delivery and photothermal treatment against cancer have been performed in vitro, $67,122,178$ hereafter we will focus on in vivo studies because they represent a more reliable model for such a complex disease as cancer. Some studies employed spherical AuNPs with siRNA for laser irradiation ${ }^{90,98}$ but as they possess an LSPR band in the visible region, in this case adjacent (nontargeted) tissues can be damaged by the irradiation. In order to avoid this unwanted effect, the use of anisotropic AuNPs that absorb in the NIR region is preferable because the absorption profile of biological structures and living organisms is significantly lower between ca. 750 and $1200 \mathrm{~nm} .{ }^{179}$ It should be taken into consideration that the irradiation conditions can strongly affect the results. For example, Braeckmans and colleagues compared the siRNA transfection efficacy of AuNPs depending on laser energy and how pores in the membrane were created either through direct heating or by 'vapour nanobubbles' produced around the AuNPs at higher laser potency. ${ }^{180}$ In the same direction, Wayteck et al. compared siRNA delivery by vapour-mediated photoporation using AuNPs and nucleofection; showing a three-fold higher number of efficiently transfected cytotoxic $T$ cells in the case of photoporation. ${ }^{173}$

Different siRNA knockdown strategies have been employed in combination with photothermal anticancer treatment, including reduction of angiogenesis and suppression of metastasis. Kwon and colleagues employed AuNPs with siRNA against VEGF administered intratumorally in PC-3 tumor bearing mice in order to deplete angiogenesis and obtain tumor ablation by laser irradiation, obtaining a complete regression of the tumor. ${ }^{98}$ Other authors made use of siRNA to supress metastasis while cancer cells were compromised by photoablation. In this instance gold nanorods with docetaxel and siRNA against p65 to block the nuclear factor kappa B pathway (important in immune response and altered in several types of cancer) were administered by intratumoral injection in orthotopically implanted 4T1 tumors. In this case, an $84 \%$ decrease of tumor growth rate was achieved and the amount of metastatic lesions found in the lungs of mice was decreased by more than 14 times. ${ }^{163}$ In the same line, Yang et al. employed siRNA against the glycolytic pyruvate kinase muscle isoenzyme PKM2 that is overexpressed in tumor cells. Here, the siRNA was carried in a layer-by-layer chitosan-gold nanorods assembly that reduced cell migration in vitro and accumulated considerably in the tumor after tail vein injection in mice. ${ }^{102}$

Another clever strategy consists of using siRNA to increase cancer cell thermal susceptibility during optical hyperthermia treatment. Although there are in vitro studies that employ siRNA and AuNPs separately to increase heat susceptibility of cells before undergoing laser irradiation, ${ }^{181}$ in vivo models typically use AuNPs functionalized with siRNA in a combined 
manner and one such study, by Lu and colleagues, reported the use of gold nanostars functionalized with siRNA against heat shock protein 72, a malignancy-specific-overexpressed thermotolerance-related chaperone. The nanostars were covered by hyaluronic acid and were injected intravenously resulting in the complete reduction of luminescence and tumor volume after laser irradiation in MDA-MB-231/Luc bearing mice models. ${ }^{63}$ In this study, nanostar biocompatibility and hemocompatibility was also studied, without showing haemolysis. A similar study performed by $\mathrm{Li}$ and co-workers focused on gold nanorod-siRNA targeting BAG3, a gene that blocks heat-shock response. Particles were administered intratumorally and, after laser treatment, tumor growth was clearly reduced in a xenograft model.62 Apart from nanorods and nanostars, hollow gold nanoshells functionalized with siRNA against heat shock protein 70, intravenously administered, have been employed in a similar strategy, showing a decrease in tumor volume and weight in nude mice bearing U87MG. ${ }^{64}$

Oncogenes are genes that codify for proteins that control cell cycle and are overexpressed in cancer cells. siRNA has also been used to prevent the division of cancer cells and to induce apoptosis. Gold nanorods carrying doxorubicin and siRNA against mutant K-Ras were administered intratumorally in pancreatic adenocarcinoma xenograft mice models. Following irradiation, the tumor volume was decreased significantly. ${ }^{160}$ Recently, Zhu and colleagues have developed gold nanorods covered with thermosensitive polymers that are internalized by the tumor cells when they are irradiated and functionalized with DNA Y-motifs, a special structure that binds the siRNA and doxorubicin until it is exposed to miRNA and ATP (such as in the cellular cytoplasm) provoking the release of doxorubicin and the siRNA against the over-expressed proto-oncogene PLK1 to produce a synergistic inhibition of tumor growth in mice. ${ }^{120}$

However, probably the most relevant photothermal treatment study was performed by Conde et al (Figure 8) ${ }^{129}$. In this study a triple-combination therapy was designed involving interference, drug and phototherapy. Gold nanorods functionalized with avastin, a vascular endothelial growth factor (VEGF) inhibitor, and gold nanospheres functionalized with siRNA against K-Ras, both of them also functionalized with a targeting peptide, were entrapped in a hydrogel patch that enhanced the stability and provided local delivery of embedded nanoparticle. When laser irradiated, mediated the conversion of near-infrared radiation into heat, causing the release of the chemotherapeutic as well as thermally induced tumor cell damage. VEGF is a signal protein produced by cells that stimulates vasculogenesis and angiogenesis while $\mathrm{K}$-Ras is a gene that performs an essential function in normal tissue signaling, but its mutation is considered to be an essential step in the development of many cancers. This hydrogel was implanted adjacent to the colorectal tumor in a mouse model and irradiated, causing a total reduction in the luciferase signal and achieving the survival of all the mice treated with the triple therapy compared to $100 \%$ mortality of the untreated mice. The authors also studied the efficacy of the triple therapy both
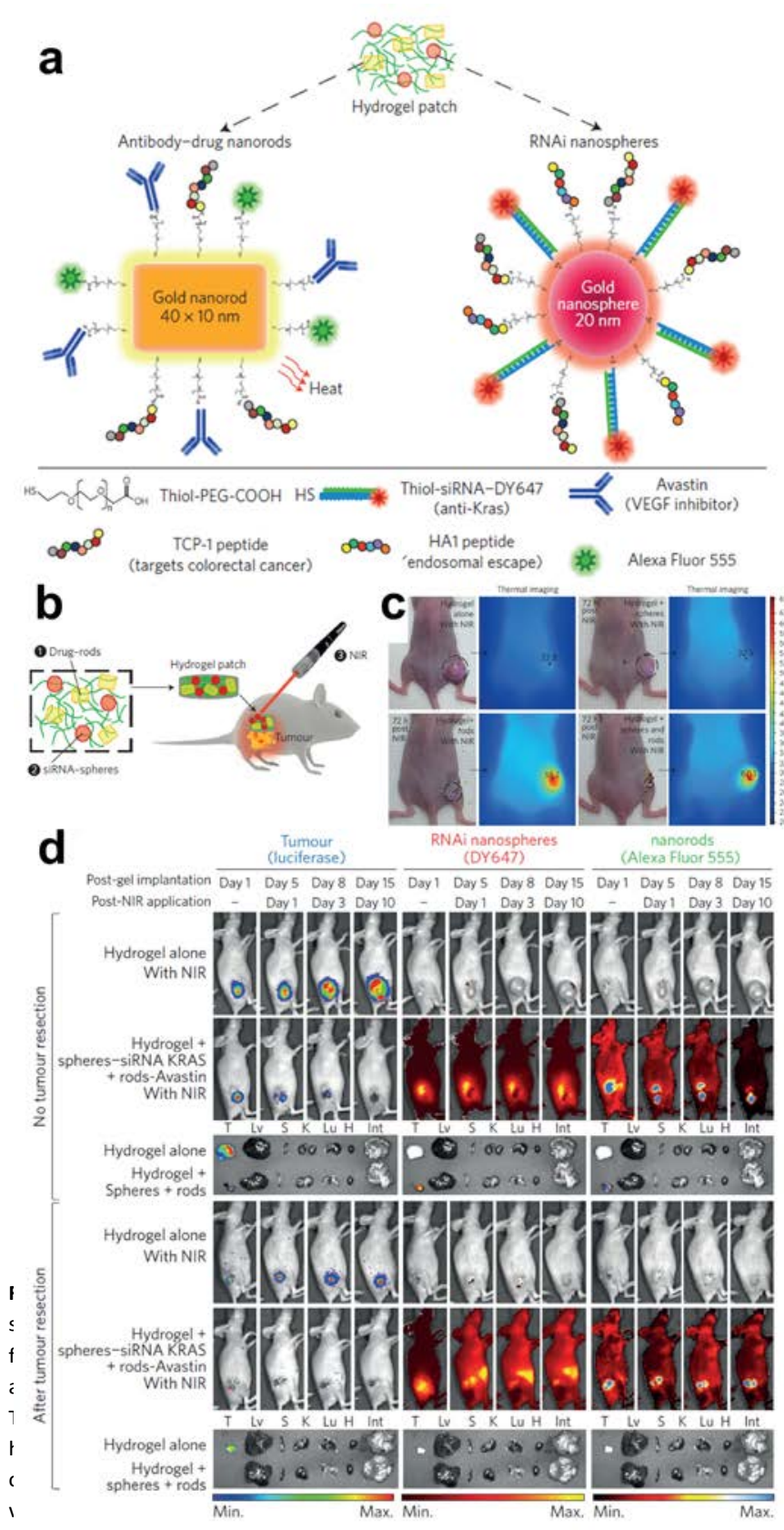

Int, intestines) and live imaging of SCID hairless congenic mice with colorectal tumor xenografts implanted with the hydrogels and the NIR treatment, either with no tumor resection or after tumor resection. Adapted with permission from 129

without tumor resection and after tumor resection, leading to a clear luciferase expression decrease compared to controls. To complete this study, a complete expression kinetics study of 20087 genes in local triple therapy was performed, showing 3589 genes altered 72 hours after the therapy. These studies achieve a new depth in the level of the study of AuNPs for siRNA by attempting to understand how the treatment affects metabolism taking one step further towards facilitating their implementation in a clinical setting.

\subsection{Entrapment of AuNPs in organic composites}


The aim of encapsulating drugs is usually to enhance drug stability, provide a sustained release, improve their effectiveness, decrease drug toxicity and/or enhance drug bioavailability. ${ }^{182} \mathrm{~A}$ variety of nanomaterials can be employed for this purpose, for example lipidic and polymeric derivatives, such as liposomes, solid lipid nanoparticles, dendrimeric nanocarriers, block copolymer micelles, cyclodextrins or hydrogel nanoparticles. However drugs encapsulated in proteins, silica or carbon nanomaterials are also common. It should be noted how siRNA encapsulation has provided the best results until now compared with other siRNA carriers, providing different clinical trials with positive conclusions (Table 1). For this reason, entrapment of AuNPs for siRNA delivery provide advantages stemming from both nanoparticle and encapsulating material, by increasing the protection of AuNPs and siRNA and providing a sustained release.

Different entrapment materials have been employed to capture siRNA-conjugated AuNP composites. Kong and colleagues employed a mixture of different cationic lipids to encapsulate hydrophobic AuNPs, forming a composite with a highly cationic surface charge that complexed efficiently to siRNA and were able to achieve gene silencing in vitro with a lower toxicity than cationic carrier polyethyleneimine. ${ }^{127} \mathrm{Oh}$ and co-workers co-entrapped siRNA and Au nanorods in Bovine Serum Albumin (BSA) nanocapsules and after grafting with PEG and anti-ErbB-2 antibodies they were able to silence the antiapoptotic protein $\mathrm{Bcl}-2$ in the target cells during approximately 72 hours and observed a synergistic effect when nanorods were laser irradiated. ${ }^{122}$ Polymer-encapsulated nanoparticles have also been employed successfully to provide RNA interference. For example, Son et al. developed a strategy to precisely control the assembly of AuNP in groups of two, three or more particles by the interaction of complementary sense and antisense strands of siRNA just controlling the number of single stranded siRNAs per AuNP. These RNAi-AuNP nanoconstructs were entrapped in branched polyethylenimine that were administered by intratumoral injection providing anticancer efficacy in mice. ${ }^{98}$ In another interesting work, Park and colleagues siRNA and AuNPs synthesized in situ on a siRNA/PEI complex were encapsulated in PEGylated hyaluronic acid, showing that AuNPs were crucial to provide siRNA stability against RNases in rat serum solution and demonstrating an accumulation of the nanocomplex in tumors by fluorescence imaging after tail administration in mice. ${ }^{183}$ Thereafter the researchers showed that this nanomaterial was able to reduce fluorescence protein expression in tumor bearing mice. In another study, gold nanoclusters were coated with polyarginine and were encapsulated in the siRNA against nerve growth factor (NGF) showing efficacy as anticancer treatment against pancreatic cancer in mice. ${ }^{184}$

One further approach is the use of niosomes for drug entrapment. Niosomes are formed by a bilayer structure similar to biological vesicles and are supposed to be biodegradable, biocompatible and nonimmunogenic. ${ }^{185}$ For siRNA delivery, Mandal and colleagues employed acidic milieu-sensitive multilamellar gold niosomes to downregulate Akt in human breast therapy-resistant cancer xenograft tumor models. ${ }^{124}$ Other approaches to increase the stability and provide local delivery can be applied, such as the employment of hydrogel patch with the embedded nanoparticles that was implanted subcutaneously on top of the mammary tumor. ${ }^{129}$ Entrapment of AuNP/siRNA constructs appears to provide all of the aforementioned advantages, but could also improve the choice of routes of administration depending on the properties of the entrapping material, for example by taking advantage of oral administration thanks to the use of the entrapping chitosan polymer. ${ }^{93,186}$ Overall, encapsulation of AuNPs could provide an additional level of control to AuNP delivery, stability and permit the use of new routes of administration avoiding the feared unknown side effects of nanoparticle accumulation.

\section{Conclusions and future perspectives}

Although AuNP-based siRNA delivery remains at a fundamental stage of development, far from being employed in a clinical setting, the innovative approaches described herewithin are testament to the many promising benefits of using nanocarriers for siRNA interference applications. It is clear that the highly modular nature of AuNP-based siRNA delivery systems offers several key advantages, since one or more design strategies can be exploited for any given application. For example, in this review we have shown how it is possible to harness active targeting methodologies based on multi-functional nanoparticles, co-delivery of other pharmaceuticals, entrapment in organic composites (for protection or targeted delivery) of the AuNPs as well as photothermal-triggered release. AuNPs also offer an improved protection to siRNA (especially against RNases) along with the possibility to achieve site-specific targeting. In addition, the observed efficacy of AuNP-based siRNA delivery in many reported in vivo studies (especially for anticancer treatments) is particularly relevant as they provide promise for future clinical trials. But perhaps their most important disadvantage is that AuNPs do tend to accumulate in tissues and organs such as the liver and spleen and, moreover, despite the 'inert' nature of gold, there is a clear lack of knowledge concerning the long-term toxicological consequences of such deposits in organs and tissues. One of the grand challenges for this area should therefore be to shed light on the longer-term toxicological effects of AuNP accumulation in vivo. Furthermore, the historic approval of (Onpattro) Patisiran from Alnylam on $10^{\text {th }}$ of August 2018 as the first-ever FDA-approved siRNA therapy is sure to serve as a driving force to once again intensify research in nanomaterial-based siRNA delivery. Importantly, the long wait for Onpattro approval demonstrates the need to continue research into alternative precision therapies in this promising field. In this respect, engineering AuNP-based siRNA nanocarriers for routes of administration that will pose lower risks of accumulation in vivo, for instance topical and oral administration, could provide a significant opportunity for AuNP-mediated siRNA delivery in a clinical setting. 


\section{Conflicts of interest}

There are no conflicts to declare.

\section{Acknowledgements}

We are grateful for the financial support provided by the Fondo Social Europeo-Gobierno de Aragón, Ministerio de la Economía y Competitividad del Gobierno de España for the public funding of Proyectos I+D+I - Programa Estatal de Investigación, Desarrollo e Innovación Orientada a los Retos de la Sociedad (project n. SAF2014-54763-C2-2-R), Ministerio de Educación, Cultura y Deportes (A.A., FPU grant (FPU014/06249)), Ministerio de Economía y Competitividad (I.S.S., FPI grant, BES2015-071304) and the Fundación General CSIC (S.G.M., Programa ComFuturo). Authors gratefully acknowledge Servier Medical Art PowerPoint image bank for most of the elements employed in the figures.

\section{Notes and references}

AA reviewed the literature and co-wrote the manuscript; SGM provided overall guidance to the development of the review and cowrote the manuscript; ISS, LDM, SGM, JMF critically reviewed and contributed ideas to various sections. All authors read and approved the final manuscript.

A. Fire, S. Xu, M. K. Montgomery, S. A. Kostas, S. E. Driver and C. C. Mello, Nature, 1998, 391, 806-811. S. M. Elbashir, J. Harborth, W. Lendeckel, A. Yalcin, K. Weber and T. Tuschl, Nature, 2001, 411, 494-498. A. P. McCaffrey, L. Meuse, T.-T. T. Pham, D. S. Conklin, G. J. Hannon and M. a Kay, Nature, 2002, 418, 38-9.

D. V. Morrissey, J. A. Lockridge, L. Shaw, K. Blanchard, K. Jensen, W. Breen, K. Hartsough, L. Machemer, S. Radka, V. Jadhav, N. Vaish, S. Zinnen, C. Vargeese, K. Bowman, C. S. Shaffer, L. B. Jeffs, A. Judge, I. MacLachlan and B. Polisky, Nat. Biotechnol., 2005, 23, 1002-1007. S. A. Leachman, R. P. Hickerson, P. R. Hull, F. J. D. Smith, L. M. Milstone, E. B. Lane, S. J. Bale, D. R. Roop, W. H. I. McLean and R. L. Kaspar, J. Dermatol. Sci., 2008, 51, 151157.
G. R. Devi, Cancer Gene Ther., 2006, 13, 819-829.

Z. Wang, D. D. Rao, N. Senzer and J. Nemunaitis, Pharm. Res., 2011, 28, 2983-2995.

E. Bernstein, A. A. Caudy, S. M. Hammond and G. J. Hannon, Nature, 2001, 409, 363-366.

T. A. Rand, K. Ginalski, N. V Grishin and X. Wang, Proc. Natl. Acad. Sci. U. S. A., 2004, 101, 14385-9.

S. L. Ameres, J. Martinez and R. Schroeder, Cell, 2007, 130, 101-112.

D. W. Bartlett and M. E. Davis, Nucleic Acids Res., 2006, 34, 322-333.

F. T. M. D. C. Vicentini, L. N. Borgheti-Cardoso, L. V. Depieri, D. De MacEdo Mano, T. F. Abelha, R. Petrilli and M. V. L. B. Bentley, Pharm. Res., 2013, 30, 915-931.

R. L. Kanasty, K. A. Whitehead, A. J. Vegas and D. G. Anderson, Mol. Ther., 2012, 20, 513-524. J. J. Turner, S. W. Jones, S. A. Moschos, M. A. Lindsay and
M. J. Gait, Mol. BioSyst., 2007, 3, 43-50.

A. D. Judge, V. Sood, J. R. Shaw, D. Fang, K. McClintock and I. MacLachlan, Nat. Biotechnol., 2005, 23, 457-462.

Y. Huang, J. Hong, S. Zheng, Y. Ding, S. Guo, H. Zhang, X. Zhang, Q. Du and Z. Liang, Mol. Ther., 2011, 19, 381-385.
18

19

20

21
White, Mol. Pharm., 2012, 9, 71-80.

R. Kanasty, J. R. Dorkin, A. Vegas and D. Anderson, Nat. Mater., 2013, 12, 967-977.

C. Schmidt, Nat. Biotechnol., 2007, 25, 273-275.

R. W. Esmond and A. K.-H. Chung, Nanotechnol. Law Bus., 2014, 11, 15-28.

P. K. Kaiser, R. C. A. Symons, S. M. Shah, E. J. Quinlan, H. Tabandeh, D. V. Do, G. Reisen, J. A. Lockridge, B. Short, R. Guerciolini and Q. D. Nguyen, Am. J. Ophthalmol., 2010, 150, 33-39.

M. E. Davis, J. E. Zuckerman, C. H. J. Choi, D. Seligson, A. Tolcher, C. A. Alabi, Y. Yen, J. D. Heidel and A. Ribas, Nature, 2010, 464, 1067-1070.

S. A. Leachman, R. P. Hickerson, M. E. Schwartz, E. E. Bullough, S. L. Hutcherson, K. M. Boucher, C. D. Hansen, M. J. Eliason, G. S. Srivatsa, D. J. Kornbrust, F. J. D. Smith, W. I. McLean, L. M. Milstone and R. L. Kaspar, Mol. Ther., 2010, 18, 442-446.

M. R. Zamora, M. Budev, M. Rolfe, J. Gottlieb, A. Humar, J. DeVincenzo, A. Vaishnaw, J. Cehelsky, G. Albert, S. Nochur, J. A. Gollob and A. R. Glanville, Am. J. Respir. Crit. Care Med., 2011, 183, 531-538.

J. Dannull, N. R. Haley, G. Archer, S. Nair, D. Boczkowski, M. Harper, N. De Rosa, N. Pickett, P. J. Mosca, J. Burchette, M. A. Selim, D. A. Mitchell, J. Sampson, D. S. Tyler and S. K. Pruitt, J. Clin. Invest., 2013, 123, 3135-3145.

B. Schultheis, D. Strumberg, A. Santel, C. Vank, F. Gebhardt, O. Keil, C. Lange, K. Giese, J. Kaufmann, M. Khan and J. Drevs, J. Clin. Oncol., 2014, 32, 4141-4148.

K. Fitzgerald, M. Frank-Kamenetsky, S. Shulga-Morskaya, A. Liebow, B. R. Bettencourt, J. E. Sutherland, R. M.

Hutabarat, V. A. Clausen, V. Karsten, J. Cehelsky, S. V Nochur, V. Kotelianski, J. Horton, T. Mant, J. Chiesa, J. Ritter, M. Munisamy, A. K. Vaishnaw, J. A. Gollob and A. Simon, Lancet., 2014, 383, 60-68.

T. Golan, E. Z. Khvalevsky, A. Hubert, R. M. Gabai, N. Hen, A. Segal, A. Domb, G. Harari, E. Ben David, S. Raskin, Y. Goldes, E. Goldin, R. Eliakim, M. Lahav, Y. Kopleman, A. Dancour, A. Shemi and E. Galun, Oncotarget, 2015, 6, 24560-24570.

J. M. Benitez-Del-Castillo, J. Moreno-Montañés, I. JiménezAlfaro, F. J. Muñoz-Negrete, K. Turman, K. Palumaa, B. Sádaba, M. V. González, V. Ruz, B. Vargas, C. Pañeda, T. Martínez, A.-M. Bleau and A. I. Jimenez, Investig. Opthalmology Vis. Sci., 2016, 57, 6447-54.

J. Conde, A. Ambrosone, Y. Hernandez, F. Tian, M. McCully, C. C. Berry, P. V. Baptista, C. Tortiglione and J. M. De La Fuente, Nano Today, 2015, 10, 421-450.

S. H. Ku, S. D. Jo, Y. K. Lee, K. Kim and S. H. Kim, Adv. Drug Deliv. Rev., 2016, 104, 16-28.

F. Eberle, K. Giessler, C. Deck, K. Heeg, M. Peter, C. Richert 
and A. H. Dalpke, J. Immunol., 2008, 180, 3229-37. S. A. Dar, A. Thakur, A. Qureshi and M. Kumar, Sci. Rep., 2016, 6, 1-8. L. B. Couto and K. A. High, Curr. Opin. Pharmacol., 2010, 10, 534-542. Y. Deng, C. C. Wang, K. W. Choy, Q. Du, J. Chen, Q. Wang, L. Li, T. K. H. Chung and T. Tang, Gene, 2014, 538, 217-227. S. Wilhelm, A. J. Tavares, Q. Dai, S. Ohta, J. Audet, H. F. Dvorak and W. C. W. Chan, Nat. Rev. Mater., 2016, 1, 1-12. E. P. Thi, C. E. Mire, A. C. H. Lee, J. B. Geisbert, J. Z. Zhou, K. N. Agans, N. M. Snead, D. J. Deer, T. R. Barnard, K. A. Fenton, I. Maclachlan and T. W. Geisbert, Nature, 2015, 521, 362-365. H. Meng, M. Liong, T. Xia, Z. Li, Z. Ji, J. I. Zink and A. E. Nel, ACS Nano, 2010, 4, 4539.

Angew. Chemie - Int. Ed., 2009, 48, 4174-4179. N. W. S. Kam, Z. Liu and H. Dai, J. Am. Chem. Soc., 2005, 127, 12492-12493.

L. Zhang, Z. Lu, Q. Zhao, J. Huang, H. Shen and Z. Zhang, Small, 2011, 7, 460-464.

M. V. Yezhelyev, L. Qi, R. M. O'Regan, S. Nie and X. Gao, J. Am. Chem. Soc., 2008, 130, 9006-9012.

J. Li, Y. C. Chen, Y. C. Tseng, S. Mozumdar and L. Huang, J. Control. Release, 2010, 142, 416-421.

A. Elbakry, A. Zaky, R. Liebl, R. Rachel, A. Goepferich and M. Breunig, Nano Lett., 2009, 9, 2059-64.

H. Lee, A. K. R. Lytton-Jean, Y. Chen, K. T. Love, A. I. Park, E. D. Karagiannis, A. Sehgal, W. Querbes, C. S. Zurenko, M. Jayaraman, C. G. Peng, K. Charisse, A. Borodovsky, M. Manoharan, J. S. Donahoe, J. Truelove, M. Nahrendorf, R. Langer and D. G. Anderson, Nat. Nanotechnol., 2012, 7, 389-393.
Y. Ding, Z. Jiang, K. Saha, C. S. Kim, S. T. Kim, R. F. Landis and V. M. Rotello, Mol. Ther., 2014, 22, 1075-1083. M. Faraday, Philos. Trans. R. Soc. London, 1857, 147, 145181.

L. Vigderman and E. R. Zubarev, Chem. Mater., 2013, 25, 1450-1457.

B. Pelaz, V. Grazu, A. Ibarra, C. Magen, P. del Pino and J. M de la Fuente, Langmuir, 2012, 28, 8965-70.

J. Piella, N. G. Bastús and V. Puntes, Chem. Mater., 2016, 28, 1066-1075.

X. Cheng, X. Tian, A. Wu, J. Li, J. Tian, Y. Chong, Z. Chai, Y. Zhao, C. Chen and C. Ge, ACS Appl. Mater. Interfaces, 2015, 7, 20568-20575.

L. Shang, K. Nienhaus and G. Nienhaus, J. Nanobiotechnology, , DOI:10.1186/1477-3155-12-5.

S. Hirn, M. Semmler-Behnke, C. Schleh, A. Wenk, J. Lipka, M. Schäffler, S. Takenaka, W. Möller, G. Schmid, U. Simon and W. G. Kreyling, Eur. J. Pharm. Biopharm., 2011, 77, 407-416.

W. H. De Jong, W. I. Hagens, P. Krystek, M. C. Burger, A. J. A. M. Sips and R. E. Geertsma, Biomaterials, 2008, 29, 1912-1919.

G. Alfranca, Á. Artiga, G. Stepien, M. Moros, S. G. Mitchell and J. M. de la Fuente, Nanomedicine (Lond.), 2016, 11,
Y. Wang, K. C. L. Black, H. Luehmann, W. Li, Y. Zhang, X. Cai, D. Wan, S.-Y. Liu, M. Li, P. Kim, Z.-Y. Li, L. V. Wang, Y. Liu and Y. Xia, ACS Nano, 2013, 7, 2068-2077.

Bioconjug. Chem., 2017, 28, 1791-1800.

L. M. Liz-Marzán, Langmuir, 2006, 22, 32-41.

M. E. Stewart, C. R. Anderton, L. B. Thompson, J. Maria, S. K. Gray, J. A. Rogers and R. G. Nuzzo, Chem. Rev., 2008, 108, 494-521.

N. Li, P. Zhao and D. Astruc, Angew. Chemie - Int. Ed., 2014, 53, 1756-1789.

J. Conde, A. Ambrosone, V. Sanz, Y. Hernandez, V. Marchesano, F. Tian, H. Child, C. C. Berry, M. R. Ibarra, P. V Baptista, C. Tortiglione and J. M. de la Fuente, ACS Nano, 2012, 6, 8316-8324.

B. K. Wang, X. F. Yu, J. H. Wang, Z. Bin Li, P. H. Li, H. Wang, L. Song, P. K. Chu and C. Li, Biomaterials, 2016, 78, 27-39. S. Wang, Y. Tian, W. Tian, J. Sun, S. Zhao, Y. Liu, C. Wang, Y. Tang, X. Ma, Z. Teng and G. Lu, ACS Nano, 2016, 10, 85788590.

Z. Wang, S. Li, M. Zhang, Y. Ma, Y. Liu, W. Gao, J. Zhang and Y. Gu, Adv. Sci., 2016, 4, 1600327.

K. Rahme, M. T. Nolan, T. Doody, G. P. McGlacken, M. A. Morris, C. O'Driscoll and J. D. Holmes, RSC Adv., 2013, 3, 21016.

Y. T. Chang, P. Y. Liao, H. S. Sheu, Y. J. Tseng, F. Y. Cheng and C. S. Yeh, Adv. Mater., 2012, 24, 3309-3314.

X. Huang, A. Pallaoro, G. Braun, D. Morales, J. Zasadzinski and N. Reich, Nano Lett., 2014, 14, 2046-2051.

C.-T. Chien, C.-Y. Liu, Z.-W. Wu, P.-J. Chen, C.-L. Chu and S.Y. Lin, J. Mater. Chem. B, 2014, 2, 6730-6737.

M. Lee, N. Kim, J. Lee, D. Lim, W. Suh, H. Kim, J. Park and J. Jeong, Macromol. Res., 2015, 23, 670-677.

Z. Wang, H. Wu, H. Shi, M. Wang, C. Huang and N. Jia, J. Mater. Chem. B, 2016, 4, 2519-2526.

Y. Chen, M. Xu, Y. Guo, K. Tu, W. Wu, J. Wang, X. Tong, W. Wu, L. Qi and D. Shi, Nanotechnology, 2017, 28, 025101.

Q. Ni, Z. Teng, M. Dang, Y. Tian, Y. Zhang, P. Huang, X. Su, N. Lu, Z. Yang, W. Tian, S. Wang, W. Liu, Y. Tang, G. Lu and L. Zhang, Nanoscale, 2017, 9, 1466-1474.

M. Mohammadniaei, T. Lee, B. G. Bharate, J. Yoon, H. K. Choi, S. jeong Park, J. Kim, J. Kim and J. W. Choi, Small, 2018, 14, 1-13.

J. H. Choi and B. K. Oh, J. Microbiol. Biotechnol., 2014, 24, 1291-1299.

X. Liu, N. Huang, H. Li, Q. Jin and J. Ji, Langmuir, 2013, 29, 9138-9148.

P. del Pino, B. Pelaz, Q. Zhang, P. Maffre, G. U. Nienhaus and W. J. Parak, Mater. Horiz., 2014, 1, 301-313.

B. D. Chithrani, A. A. Ghazani and W. C. W. Chan, Nano Lett., 2006, 6, 662-668.

L. Treuel, D. Docter, M. Maskos and R. H. Stauber, Beilstein J. Nanotechnol., 2015, 6, 857-873.

M. C. Lo Giudice, L. M. Herda, E. Polo and K. A. Dawson, Nat. Commun., 2016, 7, 13475.

P. Zhao, N. Li and D. Astruc, Coord. Chem. Rev., 2013, 257, 
638-665.

S. D. Perrault, C. Walkey, T. Jennings, H. C. Fischer and W.

C. W. Chan, Nano Lett., 2009, 9, 1909-1915.

N. T. Chen, K. C. Tang, M. F. Chung, S. H. Cheng, C. M. Huang, C. H. Chu, P. T. Chou, J. S. Souris, C. T. Chen, C. Y. Mou and L. W. Lo, Theranostics, 2014, 4, 798-807.

Z. Zhang, L. Wang, J. Wang, X. Jiang, X. Li, Z. Hu, Y. Ji, X. Wu and C. Chen, Adv. Mater., 2012, 24, 1418-1423.

A. N. Kharlamov, A. E. Tyurnina, V. S. Veselova, O. P. Kovtun, V. Y. Shur and J. L. Gabinsky, Nanoscale, 2015, 7, 8003-8015.

J. Conde, F. Tian, Y. Hernández, C. Bao, D. Cui, K. P. Janssen M. R. Ibarra, P. V. Baptista, T. Stoeger and J. M. de la Fuente, Biomaterials, 2013, 34, 7744-7753. S. Labala, A. Jose and V. V. K. Venuganti, Colloids Surfaces $B$ Biointerfaces, 2016, 146, 188-197.

L. Han, J. Zhao, X. Zhang, W. Cao, X. Hu, G. Zou, X. Duan and X. J. Liang, ACS Nano, 2012, 6, 7340-7351.

E. Zhao, Z. Zhao, J. Wang, C. Yang, C. Chen, L. Gao, Q. Feng, W. Hou, M. Gao and Q. Zhang, Nanoscale, 2012, 4, 5102.

K. Niikura, K. Kobayashi, C. Takeuchi, N. Fujitani, S.

Takahara, T. Ninomiya, K. Hagiwara, H. Mitomo, Y. Ito, Y. Osada and K. Ijiro, ACS Appl. Mater. Interfaces, 2014, 6, 22146-22154.

S. Son, J. Nam, J. Kim, S. Kim and W. J. Kim, ACS Nano 2014, 8, 5574-5584.

A. Chaudhary and S. Garg, Mater. Sci. Eng. C, 2017, 80, 1828.

X. Huang, Y. Lai, G. B. Braun and N. O. Reich, Small, 2017, 13, 1602473.

S. H. Kang, V. Revuri, S. J. Lee, S. Cho, I. K. Park, K. J. Cho, W. K. Bae and Y. K. Lee, ACS Nano, 2017, 11, 10417-10429. M. Oishi, J. Nakaogami, T. Ishii and Y. Nagasaki, Chem. Lett., 2006, 35, 1046-1047.

C. A. Mirkin, R. L. Letsinger, R. C. Mucic and J. J. Storhoff, Nature, 1996, 382, 607-609.

M. Jiwaji, M. E. Sandison, J. Reboud, R. Stevenson, R. Daly, G. Barkess, K. Faulds, W. Kolch, D. Graham, M. A. Girolami, J. M. Cooper and A. R. Pitt, PLoS One, 2014, 9, e99458.

J. Conde, F. Tian, Y. Hernandez, C. Bao, P. V. Baptista, D. Cui, T. Stoeger and J. M. de la Fuente, Nanoscale, 2015, 7, 9083-9091.

S. Son, N. Kim, D. G. You, H. Y. Yoon, J. Y. Yhee, K. Kim, I. C. Kwon and S. H. Kim, Theranostics, 2017, 7, 9-22.

S. N. Barnaby, A. Lee and C. A. Mirkin, Proc. Natl. Acad. Sci. 2014, 111, 9739-9744.

100

Z. J. Lu and D. H. Mathews, Nucleic Acids Res., 2008, 36 104-108.

101

Y. Yi, H. J. Kim, P. Mi, M. Zheng, H. Takemoto, K. Toh, B. S. Kim, K. Hayashi, M. Naito, Y. Matsumoto, K. Miyata and K. Kataoka, J. Control. Release, 2016, 244, 247-256. and S. Nie, Acta Biomater., 2015, 25, 194-204.

R. Masood, I. Roy, S. Zu, C. Hochstim, K.-T. Yong, W.-C. Law, H. Ding, U. K. Sinha and P. N. Prasad, Integr. Biol., 2012, 4 132-141.
H. S. Kim, Y. J. Son, W. Mao, K. W. Leong and H. S. Yoo,
Nano Lett., 2018, 18, 314-325.

L. Kong, J. Qiu, W. Sun, J. Yang, M. Shen, L. Wang and X. Shi, Biomater. Sci., 2017, 5, 258-266.

B. Shah, P. T. Yin, S. Ghoshal and K. B. Lee, Angew. Chemie Int. Ed., 2013, 125, 6310-6315.

S. E. Lee, D. Y. Sasaki, Y. Park, R. Xu, J. S. Brennan, M. J. Bissell and L. P. Lee, ACS Nano, 2012, 6, 7770-7780. N. Panwar, C. Yang, F. Yin, H. S. Yoon, T. S. Chuan and K. T. Yong, Nanotechnology, 2015, 26, 365101.

K. H. Min, Y. H. Kim, Z. Wang, J. Kim, J. S. Kim, S. H. Kim, K. Kim, I. C. Kwon, D. O. Kiesewetter and X. Chen, Theranostics, 2017, 7, 4240-4254.

R. Huschka, A. Barhoumi, Q. Liu, J. A. Roth, L. Ji and N. J. Halas, ACS Nano, 2012, 6, 7681-7691.

R. Bahadur K.C., B. Thapa and N. Bhattarai, Nanotechnol. Rev., 2014, 3, 269-280.

H. J. Kim, H. Takemoto, Y. Yi, M. Zheng, Y. Maeda, H. Chaya, K. Hayashi, P. Mi, F. Pittella, R. J. Christie, K. Toh, Y. Matsumoto, N. Nishiyama, K. Miyata and K. Kataoka, ACS Nano, 2014, 8, 8979-8991.

Y. Xiao, R. Jaskula-Sztul, A. Javadi, W. Xu, J. Eide, A. Dammalapati, M. Kunnimalaiyaan, H. Chen and S. Gong, Nanoscale, 2012, 4, 7185.

Z. Tang, Y. Wang, P. Podsiadlo and N. A. Kotov, Adv. Mater., 2006, 18, 3203-3224.

S. K. Lee, B. Law and C. H. Tung, Macromol. Biosci., 2017, 17, 1600294.

A. M. Paul, Y. Shi, D. Acharya, J. R. Douglas, A. Cooley, J. F. Anderson, F. Huang and F. Bai, J. Gen. Virol., 2014, 95, 1712-1722.

S. K. Lee and C. H. Tung, Adv. Funct. Mater., 2013, 23, 3488-3493.

M. Uz, S. K. Mallapragada and S. A. Altinkaya, Rsc Adv. 2015, 5, 43515-43527.

B. Esteban-Fernández De Ávila, C. Angell, F. Soto, M. A Lopez-Ramirez, D. F. Báez, S. Xie, J. Wang and Y. Chen, ACS Nano, 2016, 10, 4997-5005.

P. Zhang, C. Wang, J. Zhao, A. Xiao, Q. Shen, L. Li, J. Li, J. Zhang, Q. Min, J. Chen, H. Y. Chen and J. J. Zhu, ACS Nano, 2016, 10, 3637-3647.

R. Kotcherlakotaa, D. J. Srinivasanb, S. Mukherjeea, M. M. Haroon, G. H. Dar, U. Venkatraman, C. R. Patra and V. Gopal, J. Mater. Chem. B, 2017, 5, 7082-7098.

J.-H. Choi, H.-J. Hwang, S. W. Shin, J.-W. Choi, S. H. Um and B.-K. Oh, Nanoscale, 2015, 7, 9229-9237.

J. Gilleron, W. Querbes, A. Zeigerer, A. Borodovsky, G. Marsico, U. Schubert, K. Manygoats, S. Seifert, C. Andree, M. Stöter, H. Epstein-Barash, L. Zhang, V. Koteliansky, K. Fitzgerald, E. Fava, M. Bickle, Y. Kalaidzidis, A. Akinc, M. Maier and M. Zerial, Nat. Biotechnol., 2013, 31, 638-646. S. Rajput, N. Puvvada, B. N. P. Kumar, S. Sarkar, S. Konar, R. Bharti, G. Dey, A. Mazumdar, A. Pathak, P. B. Fisher and M. Mandal, Mol. Pharm., 2015, 12, 4214-4225.

S. K. Mudedla, E. R. Azhagiya Singam, K. Balamurugan and V. Subramanian, Phys. Chem. Chem. Phys., 2015, 17, 30307-30317.

X. Xie, S. Xu, P. Pi, J. Cheng and X. Wen, Am. Inst. Chem. 
Eng. J., 2018, 64, 810-821.

127 W. H. Kong, K. H. Bae, S. D. Jo, J. S. Kim and T. G. Park, Pharm. Res., 2012, 29, 362-374.

128 L. Fan, Y. Zhang, F. Wang, Q. Yang, J. Tan, R. Grifantini, H. Wu, C. Song and B. Jin, Biomaterials, 2016, 76, 399-407.

129 J. Conde, N. Oliva, Y. Zhang and N. Artzi, Nat. Mater., 2016, 15, 1128-1138.

130 T. A. Ignatowski, R. Aalinkeel, J. L. Reynolds, B. B. Nair, D. E. Sykes, C. P. K. Gleason, W. C. Law, M. J. Mammen, P. N. Prasad, S. A. Schwartz and S. D. Mahajan, J. Neuroimmune Pharmacol., 2015, 10, 136-152.

131 D. Zheng, D. A. Giljohann, D. L. Chen, M. D. Massich, X.-Q. Wang, H. Iordanov, C. A. Mirkin and A. S. Paller, Proc. Natl. Acad. Sci., 2012, 109, 11975-11980.

132 H. W. Child, Y. Hernandez, J. Conde, M. Mullin, P. Baptista, J. M. de la Fuente and C. C. Berry, Nanomedicine (Lond)., 2015, 10, 2513-2525.

133 J. L. Reynolds, W. C. Law, S. D. Mahajan, R. Aalinkeel, B. Nair, D. E. Sykes, K. T. Yong, R. Hui, P. N. Prasad and S. A. Schwartz, J. Neuroimmune Pharmacol., 2012, 7, 673-685.

134 H. Nemati, M. H. Ghahramani, R. Faridi-Majidi, B. Izadi, G. Bahrami, S. H. Madani and G. Tavoosidana, J. Control. Release, 2017, 268, 259-268.

135 X. Zhao, Q. Huang and Y. Jin, Mater. Sci. Eng. C, 2015, 54, 142-149.

136 W. Feng, H. Guo, T. Xue, X. Wang, C. Tang, B. Ying, H. Gong and G. Cui, RSC Adv., 2016, 6, 60171-60179.

137 P. S. Randeria, M. A. Seeger, X.-Q. Wang, H. Wilson, D. Shipp, C. A. Mirkin and A. S. Paller, Proc. Natl. Acad. Sci., 2015, 112, 5573-5578.

138 S. Sajeesh, J. Y. Choe and D. ki Lee, Nanomedicine (Lond.), 2017, 12, 2271-2286.

139 T. Lobovkina, G. B. Jacobson, E. Gonzalez-Gonzalez, R. P. Hickerson, D. Leake, R. L. Kaspar, C. H. Contag and R. N. Zare, ACS Nano, 2011, 5, 9977-9983.

140 P. Majumder, S. Bhunia and A. Chaudhuri, Chem. Commun., 2018, 54, 1489-1492.

141 S. Rietwyk and D. Peer, ACS Nano, 2017, 11, 7572-7586.

142 P. Majumder, S. Bhunia, J. Bhattacharyya and A. Chaudhuri, J. Control. Release, 2014, 180, 100-108.

143 Y. Jiang, S. Huo, J. Hardie, X.-J. Liang and V. M. Rotello, Expert Opin. Drug Deliv., 2016, 13, 547-559.

144 W. G. Kreyling, A. M. Abdelmonem, Z. Ali, F. Alves, M. Geiser, N. Haberl, R. Hartmann, S. Hirn, D. J. De Aberasturi, K. Kantner, G. Khadem-Saba, J. M. Montenegro, J. Rejman, T. Rojo, I. R. De Larramendi, R. Ufartes, A. Wenk and W. J. Parak, Nat. Nanotechnol., 2015, 10, 619-623.

145 M. Pérez-Hernández, M. Moros, G. Stepien, P. del Pino, S. Menao, M. de las Heras, M. Arias, S. G. Mitchell, B. Pelaz, E. M. Gálvez, J. M. de la Fuente and J. Pardo, Part. Fibre Toxicol., 2017, 14, 1-20.

146 S. M. Dizaj, S. Jafari and A. Y. Khosroushahi, Nanoscale Res. Lett., 2014, 9, 1-9.

147 S. K. Surapaneni, S. Bashir and K. Tikoo, Sci. Rep., 2018, 8, 1-12.

148 Y. H. Bae and K. Parkb, J Control Release, 2011, 153, 198205.
M. Mitra, M. Kandalam, J. Rangasamy, B. Shankar, U. K. Maheswari, S. Swaminathan and S. Krishnakumar, Mol. Vis., 2013, 19, 1029-38.

S. Acharya and R. A. Hill, Nanomedicine Nanotechnology, Biol. Med., 2014, 10, 329-337.

L. Gamrad, C. Rehbock, A. M. Westendorf, J. Buer, S. Barcikowski and W. Hansen, Sci. Rep., 2016, 6, 28709. K. A. Fitzgerald, K. Rahme, J. Guo, J. D. Holmes and C. M. O'Driscoll, J. Mater. Chem. B, 2016, 4, 2242-2252.

N. Li, H. Yang, Z. Yu, Y. Li, W. Pan, H. Wang and B. Tang, Chem. Sci., 2017, 8, 2816-2822.

H. Zhu, W. Liu, Z. Cheng, K. Yao, Y. Yang, B. Xu and G. Su, Int. J. Mol. Sci., 2017, 18, 2029.

C. Bechara and S. Sagan, FEBS Lett., 2013, 587, 1693-1702. N. Chanda, V. Kattumuri, R. Shukla, A. Zambre, K. Katti, A. Upendran, R. R. Kulkarni, P. Kan, G. M. Fent, S. W. Casteel, C. J. Smith, E. Boote, J. D. Robertson, C. Cutler, J. R. Lever, K. V. Katti and R. Kannan, Proc. Natl. Acad. Sci., 2010, 107, 8760-8765.

E. C. Dreaden, L. A. Austin, M. A. Mackey and M. A. ElSayed, Ther Deliv, 2012, 3, 457-478.

S. Labala, A. Jose, S. R. Chawla, M. S. Khan, S. Bhatnagar, O. P. Kulkarni and V. V. K. Venuganti, Int. J. Pharm., 2017, 525, 407-417.

R. A. Sperling and W. J. Parak, Philos. Trans. R. Soc. A Math. Phys. Eng. Sci., 2010, 368, 1333-1383.

F. Yin, C. Yang, Q. Wang, S. Zeng, R. Hu, G. Lin, J. Tian, S. Hu, R. F. Lan, H. S. Yoon, F. Lu, K. Wang and K. T. Yong, Theranostics, 2015, 5, 818-833.

L. Ding, R. Sun and X. Zhang, Oncotarget, 2017, 8, 2120021211.

M. Li, Y. Li, X. Huang and X. Lu, J. Biomater. Sci. Polym. Ed., 2015, 26, 813-827.

D. Wang, T. Wang, Z. Xu, H. Yu, B. Feng, J. Zhang, C. Guo, Q Yin, Z. Zhang and Y. Li, Small, 2016, 12, 488-498.

F. Perche, Y. Yi, L. Hespel, P. Mi, A. Dirisala, H. Cabral, K. Miyata and K. Kataoka, Biomaterials, 2016, 90, 62-71. C. J. Bishop, S. Y. Tzeng and J. J. Green, Acta Biomater., 2015, 11, 393-403.

M. E. Muroski, J. M. Kogot and G. F. Strouse, J. Am. Chem. Soc., 2012, 134, 19722-19730.

J. Liu, C. Detrembleur, B. Grignard, M. C. De Pauw-Gillet, S. Mornet, M. Treguer-Delapierre, Y. Petit, C. Jérôme and $E$. Duguet, Chem. - An Asian J., 2014, 9, 275-288. E. Polo, P. del Pino, B. Pelaz, V. Grazu and J. M. de la Fuente, Chem. Commun., 2013, 49, 3676.

A. Sguassero, Á. Artiga, C. Morasso, R. R. Jimenez, R. M. Rapún, R. Mancuso, S. Agostini, A. Hernis, A. Abols, A. Lin, A. Gualerzi, S. Picciolini, M. Bedoni, M. Rovaris, F. Gramatica, J. M. De Fuente and R. Vanna, Anal. Bioanal. Chem., 2018, 1-13.

J. Han, J. Zhang, M. Yang, D. Cui and J. M. de la Fuente, Nanoscale, 2016, 8, 492-499.

M. Pérez-Hernández, P. Del Pino, S. G. Mitchell, M. Moros, G. Stepien, B. Pelaz, W. J. Parak, E. M. Gálvez, J. Pardo and J. M. De La Fuente, ACS Nano, 2015, 9, 52-61.

D. Heinemann, M. Schomaker, S. Kalies, M. Schieck, R. 
Carlson, H. M. Escobar, T. Ripken, H. Meyer and A. Heisterkamp, PLoS One, 2013, 8, e58604.

173 L. Wayteck, R. Xiong, K. Braeckmans, S. C. De Smedt and K. Raemdonck, J. Control. Release, 2017, 267, 154-162.

174 R. S. Riley, M. N. Dang, M. Marie, B. Abraham, L. Gundlach and E. S. Day, Nano Lett., ,

DOI:10.1021/acs.nanolett.8b00681

175 F. Li, C. Li, J. Liu, X. Liu, L. Zhao, T. Bai, Q. Yuan, X. Kong, Y. Han, Z. Shi and S. Feng, Nanoscale, 2013, 5, 6950-6959.

176 A. Taruttis, N. Lozano, A. Nunes, D. A. Jasim, N. Beziere, E. Herzog, K. Kostarelos and V. Ntziachristos, Nanoscale, 2014, 6, 13451-13456.

177 X. Huang, Q. Hu, G. B. Braun, A. Pallaoro, D. P. Morales, J. Zasadzinski, D. O. Clegg and N. O. Reich, Biomaterials, 2015, 63, 70-79.

178 J. Shen, H. C. Kim, C. Mu, E. Gentile, J. Mai, J. Wolfram, L. N. $\mathrm{Ji}$, M. Ferrari, Z. wan Mao and H. Shen, Adv. Healthc. Mater., 2014, 3, 1629-1637.

179 Y. Huang, A. C. Chen and M. Hamblin, SPIE Newsroom, 2009, 9, 1-3.

180 R. Xiong, K. Raemdonck, K. Peynshaert, I. Lentacker, I. De Cock, J. Demeester, S. C. De Smedt, A. G. Skirtach and K. Braeckmans, ACS Nano, 2014, 8, 6288-6296.

181 M. R. K. Ali, H. R. Ali, C. R. Rankin and M. A. El-Sayed, Biomaterials, 2016, 102, 1-8.

182 N. A. Liechty, W. B., Kryscio, D.R., Slaughter, B. V. and Peppas, Annu. Rev. Chem. Biomol. Eng., 2010, 1, 149-173.

183 R. Heo, H. Y. Yoon, H. Ko, J. M. Shin, J. Jeon, Y. S. Chae, Y. M. Kang, D. Kim, D. S. Lee and J. H. Park, Chem. Commun., 2015, 51, 16656-16659.

184 Y. Lei, L. Tang, Y. Xie, Y. Xianyu, L. Zhang, P. Wang, Y. Hamada, K. Jiang, W. Zheng and X. Jiang, Nat. Commun., 2017, 8, 15130.

185 D. A. Seleci, M. Seleci, J. G. Walter, F. Stahl and T. Scheper, J. Nanomater., , DOI:10.1155/2016/7372306.

186 Á. Artiga, S. García-Embid, L. De Matteis, S. G. Mitchell and J. M. de la Fuente, Front. Chem., 2018, 6, 1-10.

187 E. C. Dreaden, A. M. Alkilany, X. Huang, C. J. Murphy and M. A. El-Sayed, Chem. Soc. Rev., 2012, 41, 2740-2779. 